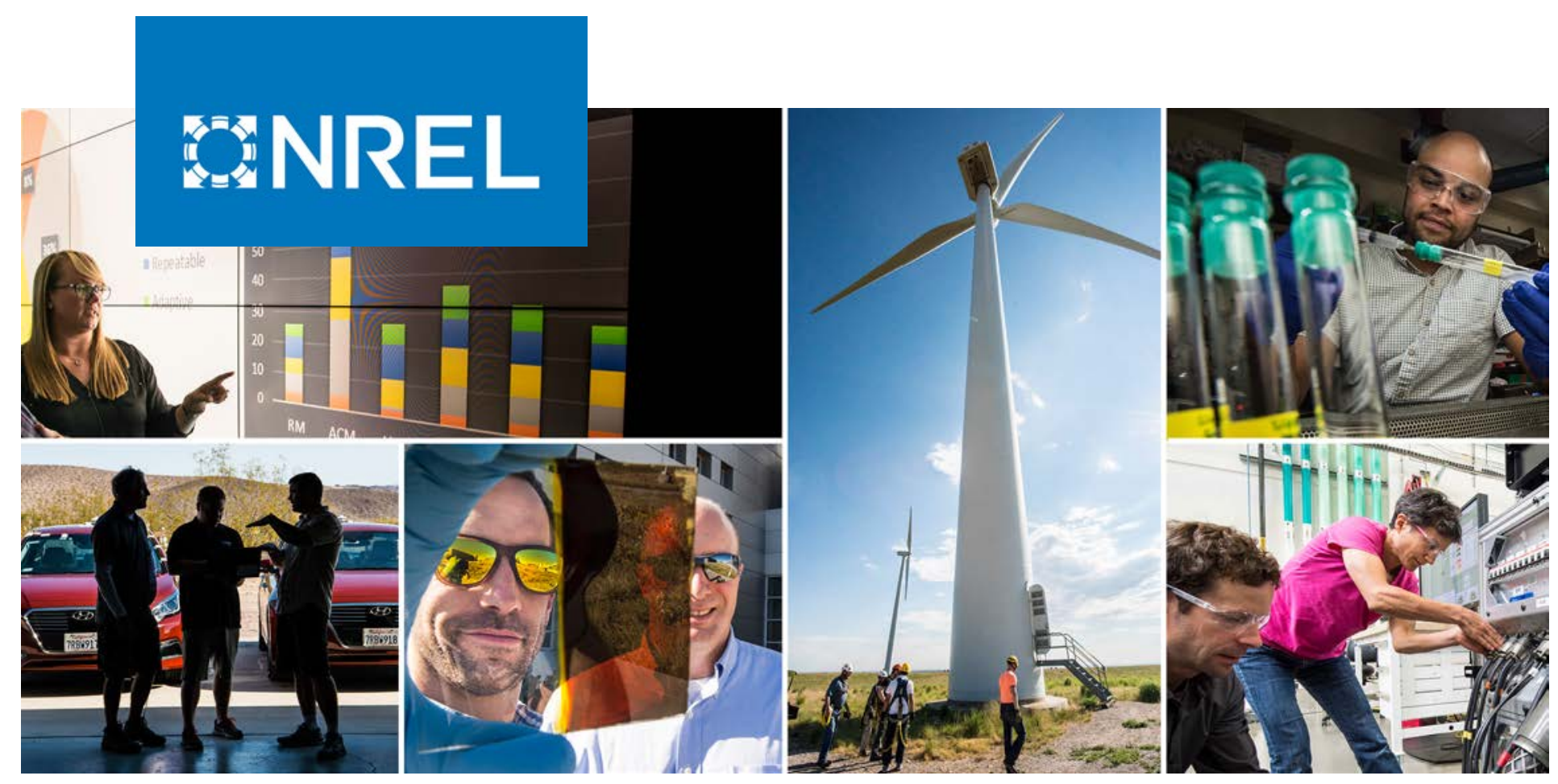

\title{
Meeting 2025 Zero Emission Vehicle Goals: An Assessment of Electric Vehicle Charging Infrastructure in Maryland
}

Matthew Moniot, Clément Rames, and Eric Wood

National Renewable Energy Laboratory

NREL is a national laboratory of the U.S. Department of Energy Office of Energy Efficiency \& Renewable Energy

Operated by the Alliance for Sustainable Energy, LLC

This report is available at no cost from the National Renewable Energy Laboratory (NREL) at www.nrel.gov/publications.

\section{Technical Report}

NREL/TP-5400-71198

February 2019 


\title{
BNREL
}

\section{Meeting 2025 Zero Emission Vehicle Goals: An Assessment of Electric Vehicle Charging Infrastructure in Maryland}

\author{
Matthew Moniot, Clément Rames, and Eric Wood
}

National Renewable Energy Laboratory

\section{Suggested Citation}

Moniot, Matthew, Clément Rames, and Eric Wood. 2019. Meeting 2025 Zero Emission Vehicle Goals: An Assessment of Electric Vehicle Charging Infrastructure in Maryland. Golden, CO: National Renewable Energy Laboratory. NREL/TP-5400-71198.

https://www.nrel.gov/docs/fy19osti/71198.pdf.

NREL is a national laboratory of the U.S. Department of Energy Office of Energy Efficiency \& Renewable Energy Operated by the Alliance for Sustainable Energy, LLC

This report is available at no cost from the National Renewable Energy Laboratory (NREL) at www.nrel.gov/publications.

Contract No. DE-AC36-08GO28308
Technical Report NREL/TP-5400-71198 February 2019

National Renewable Energy Laboratory 15013 Denver West Parkway Golden, CO 80401

303-275-3000 • www.nrel.gov 


\section{NOTICE}

This work was authored by the National Renewable Energy Laboratory, operated by Alliance for Sustainable Energy, LLC, for the U.S. Department of Energy (DOE) under Contract No. DE-AC36-08GO28308. Funding provided by Potomac Power Company under agreement FIA-18-1870. The views expressed herein do not necessarily represent the views of the DOE or the U.S. Government.

This report is available at no cost from the National Renewable Energy Laboratory (NREL) at www.nrel.gov/publications.

U.S. Department of Energy (DOE) reports produced after 1991 and a growing number of pre-1991 documents are available free via www.OSTI.gov.

Cover Photos by Dennis Schroeder: (clockwise, left to right) NREL 51934, NREL 45897, NREL 42160, NREL 45891, NREL 48097, NREL 46526.

NREL prints on paper that contains recycled content. 


\section{Acknowledgments}

This study was funded through an agreement between the National Renewable Energy Laboratory (NREL) and Potomac Electric Power Company. The authors would specifically like to thank Robert Stewart and Douglas Micheel for their support. Additional thanks to Marissa Gillett (formerly of the Maryland Public Services Commission) for her efforts in coordinating the partnership between NREL and Potomac Electric.

The Electric Vehicle Infrastructure Projection (EVI-Pro) model used in this study was developed in collaboration with the California Energy Commission. Special thanks to Kadir Bedir, Noel Crisostomo, Jennifer Allen, and Charles Smith for their support of EVI-Pro. Additional development has also been supported by the U.S. Department of Energy's Vehicle Technologies Office. The authors would specifically like to thank Michael Berube, Jacob Ward, Rachael Nealer, and Kelly Fleming for their support.

Global positioning system (GPS) travel trajectories underlying this analysis have been provided by INRIX and made available to NREL through an agreement with the Maryland State Highway Administration and the University of Maryland's Center for Advanced Transportation Technology. Special thanks to Rick Schuman (INRIX) and Thomas Jacobs (University of Maryland) for facilitating this agreement.

Reviews conducted by the Electric Power Research Institute (EPRI), the University of Texas at Austin, and the University of Washington were critical in ensuring a high level of quality in this analysis. Special thanks to Jamie Dunckley, Kara Kockelman, and Don MacKenzie respectively. 


\section{List of Acronyms}

BEV

BEVxx

DCFC

EVI-Pro

GPS

HEV

IHS

$\mathrm{kW}$

L1

L2

LDV

MUD

NREL

PEV

PHEV

PHEVxx

SUD

VMT battery electric vehicle

battery electric vehicle with a range of $\mathrm{xx}$ miles direct current fast charge

Electric Vehicle Infrastructure Projection Tool

global positioning system

hybrid electric vehicle

IHS Markit

kilowatt

Level 1 charging station

Level 2 charging station

light-duty vehicle

multiple-unit dwelling

National Renewable Energy Laboratory

plug-in electric vehicle (BEV or PHEV)

plug-in hybrid electric vehicle

plug-in hybrid electric vehicle with a range of $\mathrm{xx}$ miles single-unit dwelling

vehicle miles travelled 


\section{Table of Contents}

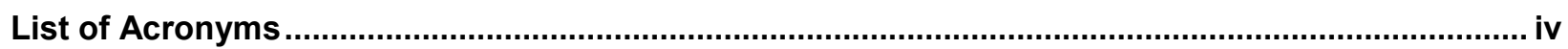

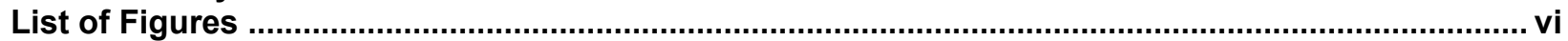

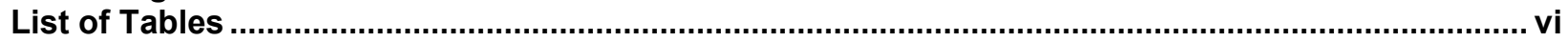

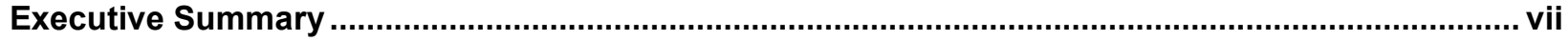

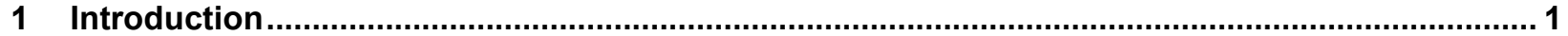

2 Maryland Existing Light-Duty Vehicle Stock and Public Charging Networks............................... 2

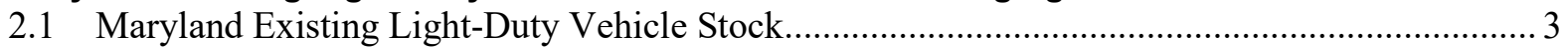

2.2 Maryland Existing Public Charging Networks ….................................................................. 5

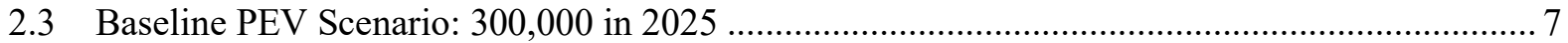

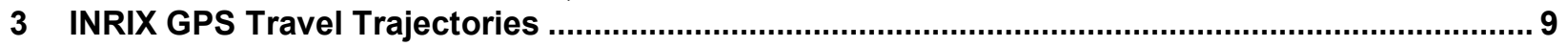

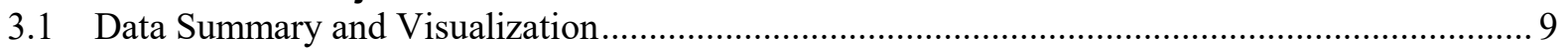

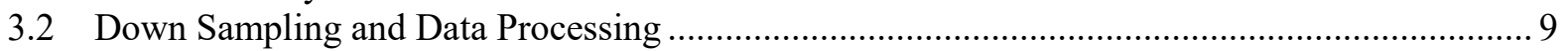

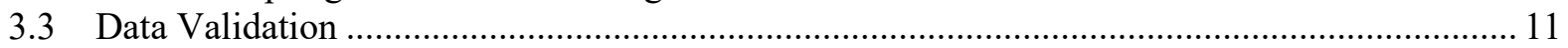

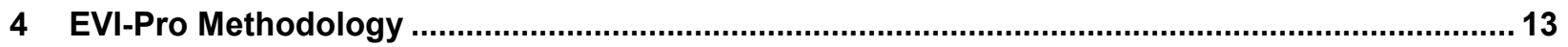

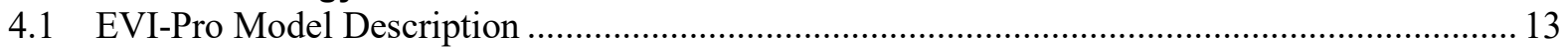

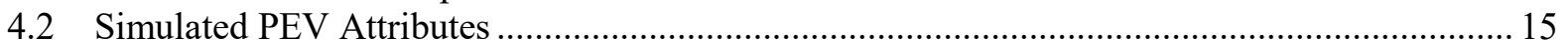

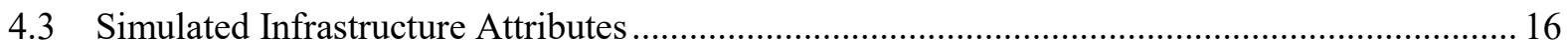

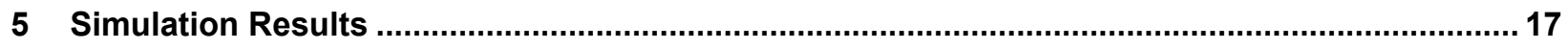

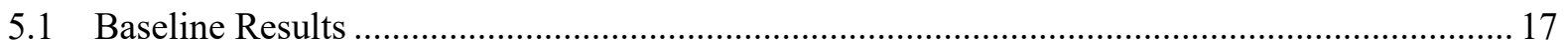

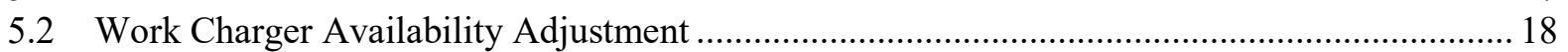

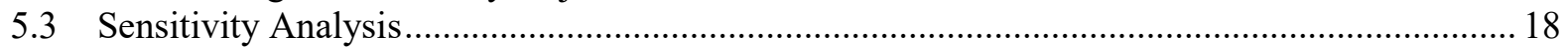

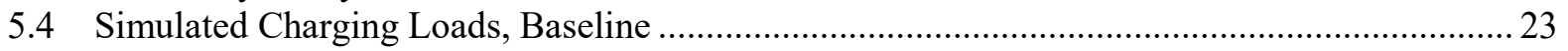

5.5 Simulated Charging Loads, Time of Use Response …........................................................ 25

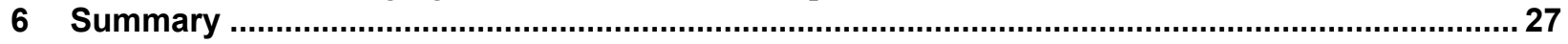

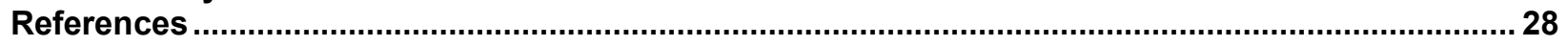

Appendix A. Existing Plug Counts by Utility Service Territory and County................................... 30

Appendix B. Maryland Housing Stock by Size and Ownership Status (with NREL Assumptions

Regarding Potential Availability of Home Charging) …............................................................. 31

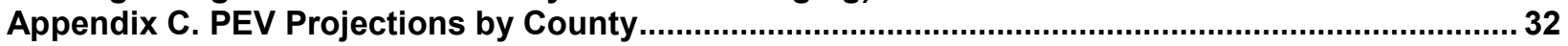

Appendix D. Electric Vehicle Supply Equipment Projections by County ............................................33

Appendix E. Select Load Profiles from Sensitivity Analysis ........................................................ 34 


\section{List of Figures}

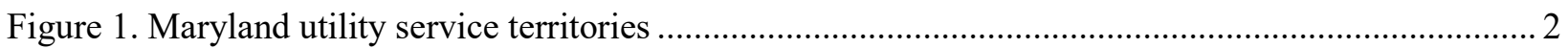

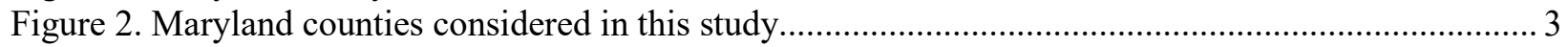

Figure 3. LDVs registered in Maryland as of the end of 2016 by fuel type ............................................. 3

Figure 4. Maryland LDV registrations by ZIP code ........................................................................ 4

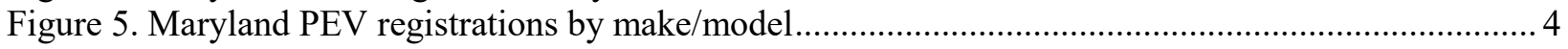

Figure 6. Existing public PEV charging infrastructure in Maryland ..................................................5

Figure 7. Existing public PEV charging plug counts in Maryland by electric utility ............................... 6

Figure 8. Maryland combined PEV and HEV registrations by ZIP code. .......................................... 7

Figure 9. Trip-destination frequency map derived from the INRIX travel data set................................ 10

Figure 10. Distribution of daily VMT from processed INRIX data and additional GPS datasets.............. 12

Figure 11. Distribution of trips by time of day from processed INRIX data and additional GPS datasets. 12

Figure 12. Graphical representation of inputs/outputs and data flow in EVI-Pro...

Figure 13. Results of parametric sensitivity analysis for non-residential (work and public) L2 plugs (top) and fast charging (bottom).

Figure 14. Aggregate statewide load profiles for a weekday, baseline .................................................. 23

Figure 15. Statewide load profiles by charging type for a weekday, separated by residence type............. 24

Figure 16. Statewide load profiles by charging type for a weekday, separated by vehicle type. The

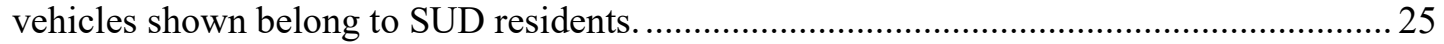

Figure 17. Aggregate statewide load profiles for a weekday with baseline assumptions and an applied

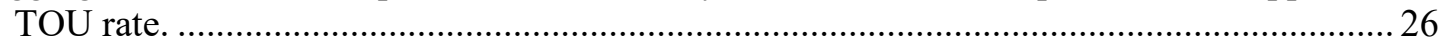

Figure E1. Aggregate statewide weekday load profiles with 30\% MUD share. Top: No residential charging at MUDs. Bottom: L2 residential charging available at MUDs............................ 34

Figure E2. Aggregate statewide weekday load profiles. Top: 4:1 PHEV:BEV ratio. Bottom: 1:4 PHEV:BEV ratio. 35

Figure E3. Aggregate statewide weekday load profiles. Top: Short-range PEV scenario. Bottom: Longrange PEV scenario.

\section{List of Tables}

Table 1. Maryland Utility Service Territories Considered in this Study by Reporting Aggregation Level.. 2 Table 2. Maryland PEV registrations by utility service territory .......................................................... 5

Table 3. Projected 2025 PEV Counts by Type and Utility Service Territory ........................................ 8

Table 4. Comparison of daily VMT between urban and rural areas .................................................. 11

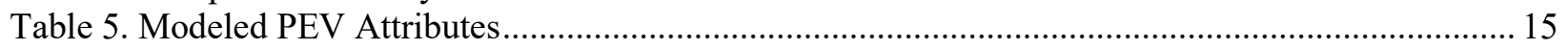

Table 6. Charging Options Available to Consumers in EVI-Pro ........................................................... 16

Table 7. Estimated Plug Counts by Utility Service Territory …........................................................ 17 


\section{Executive Summary}

In 2017 the Maryland Public Services Commission established the PC44 working group on electric vehicles to assess the potential for the state's electric utilities to adopt an electric vehicle portfolio, which would include mechanisms for electric utilities to potentially finance, install, and operate charging infrastructure within Maryland. To this end, a motion was proposed before the Maryland Public Services Commission in January of 2018 titled "In the Matter of the Petition of the Electric Vehicle Work Group for Implementation of a Statewide Electric Vehicle Portfolio" (case number 9478). As part of this proposal, the National Renewable Energy Laboratory (NREL) has been enlisted to conduct a statewide assessment of the electric vehicle charging infrastructure requirements for Maryland to meet its goal of supporting 300,000 zero emission vehicles by 2025 .

NREL's Electric Vehicle Infrastructure Projection Tool (EVI-Pro) was used to generate scenarios of statewide charging infrastructure to support consumer PEV adoption based on travel patterns provided by INRIX (a commercial mapping/traffic company) that are used to characterize regional travel in Maryland and anticipate future demand for PEV charging. This report provides guidance on PEV charging infrastructure to stakeholders in Maryland to reduce range anxiety as a barrier to PEV sales and ensure the effective use of private/public investments in PEV charging infrastructure.

Results indicate that significant expansion of Maryland's electric vehicle charging infrastructure will be required to support the state's PEV goal for 2025. Analysis shows that a fleet of 300,000 PEVs will require 17,400 workplace Level 2 plugs, 9,300 public Level 2 plugs, and 1,000 fast charge plugs. These estimates assume that future PEVs will be driven in a manner consistent with present day gasoline vehicles and that the majority of charging will happen at residential locations. A sensitivity study explores edge cases pertaining to several assumptions, highlighting factors that heavily influence the projected infrastructure requirements. Variations in the makeup of the PEV fleet, evolving consumer charging preferences, and availability of residential charging are all shown to influence 2025 infrastructure requirements. 


\section{Introduction}

As a member of the Multi-State Zero Emission Vehicle Task Force, Maryland has adopted a public goal of supporting 300,000 plug-in electric vehicles (PEVs) within the state by 2025 (O'Malley et al. 2013). Successfully meeting this goal will provide the state with widely recognized benefits, including lower vehicle operational and maintenance costs for consumers, reduced greenhouse gas emissions, improved air quality, reduced dependence on petroleum, and potential positive synergies with the electric grid (Melaina et al. 2016).

Meeting Maryland's Zero Emission Vehicle goal will require coordination among many stakeholders, including consumers, automotive manufacturers, electric utilities, electric vehicle charging companies, state/local governments, and research organizations. As part of this coordination, a convenient and effective charging network must be deployed across the region. This network should allow long-distance travel for battery electric vehicles (BEVs), empower residents who do not have access to residential charging, and provide convenient charging options for all PEV drivers. This report seeks to provide guidance on PEV charging infrastructure to stakeholders in Maryland, both to reduce range anxiety as a barrier to PEV sales and to ensure the effective use of private/public investments in PEV charging infrastructure.

This report is organized into four main parts. First, an analysis of the existing Maryland lightduty vehicle (LDV) market is conducted and PEV adoption goals are reviewed. Second, detailed global positioning system (GPS) travel data from INRIX (a commercial traffic/mapping provider) are described, including a discussion of quality control measures. Third, these travel data are used in the National Renewable Energy Laboratory's (NREL's) Electric Vehicle Infrastructure Projection (EVI-Pro) model to estimate the total amount of charging infrastructure by type and location required to support PEV adoption goals in Maryland. Finally, results are presented for a baseline scenario in Maryland supporting 300,000 PEVs, and a sensitivity analysis is conducted to highlight sources of uncertainty. 


\section{Maryland Existing Light-Duty Vehicle Stock and Public Charging Networks}

While most of the results in this study are reported at the state level, charging infrastructure estimates are also provided at the utility service territory and county levels where appropriate. The geographies used for segmenting results are shown in Figure 1 and Figure 2. Note that the geographies vary in area, population, and vehicle registrations. For the sake of simplicity, results for the six smallest utility service territories (as measured by LDV registrations) are consolidated as shown in Table 1.

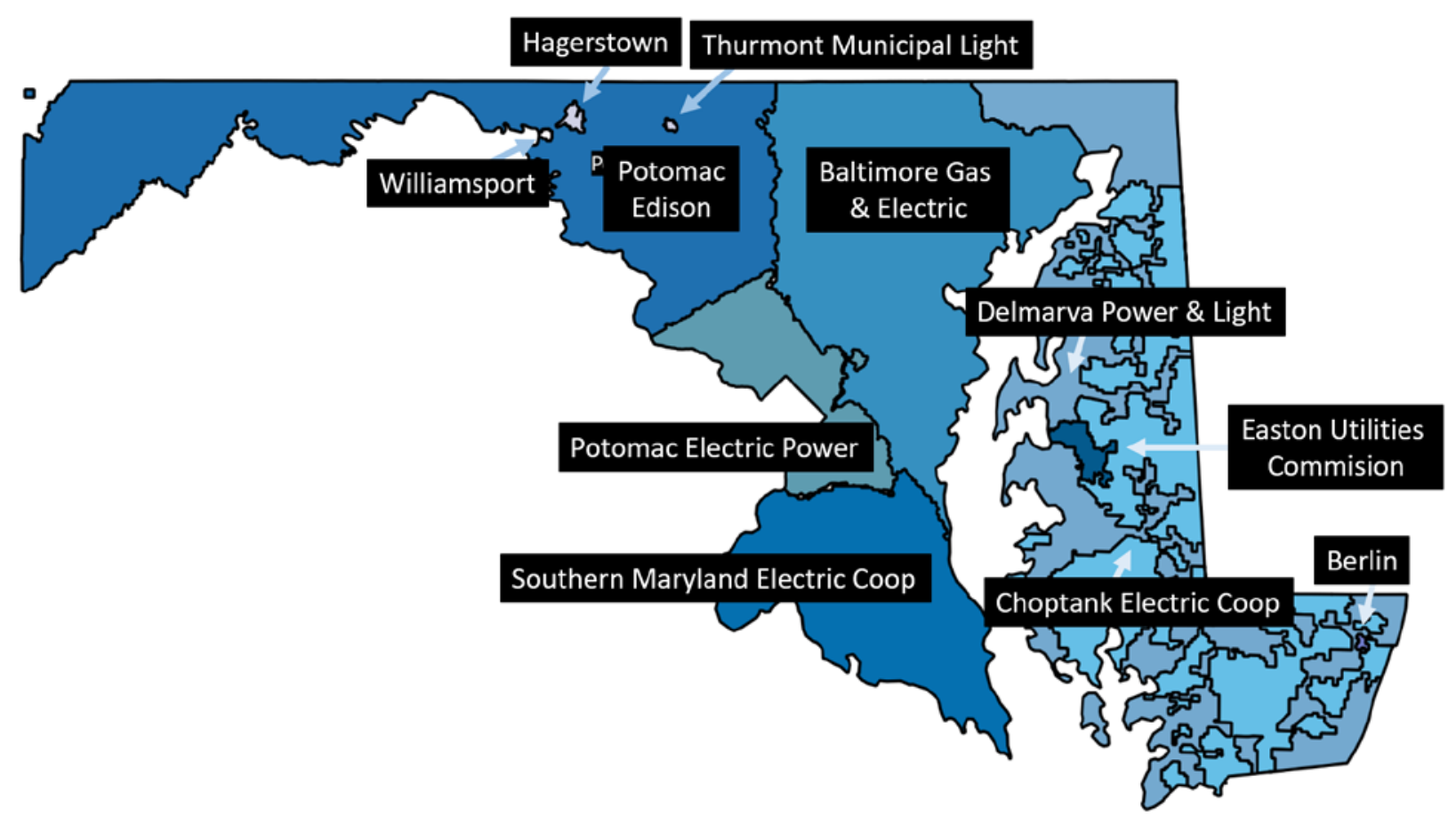

Figure 1. Maryland utility service territories

(ABB Ability Energy Velocity Suite 2018).

Table 1. Maryland Utility Service Territories Considered in this Study by Reporting Aggregation Level

\begin{tabular}{ll} 
Individual Reporting by Utility & Aggregated Reporting \\
\hline Baltimore Gas \& Electric Company (BGE) & City of Hagerstown, Maryland \\
Potomac Electric Power Company (Pepco) & Choptank Electric Coop Incorporated \\
Potomac Edison Company (PE) & Easton Utilities Commission \\
Southern Maryland Electric Coop Incorporated & Thurmont Municipal Light Company \\
(SMECO) & Town of Berlin, Maryland \\
Delmarva Power \& Light Company & Town of Williamsport, Maryland
\end{tabular}




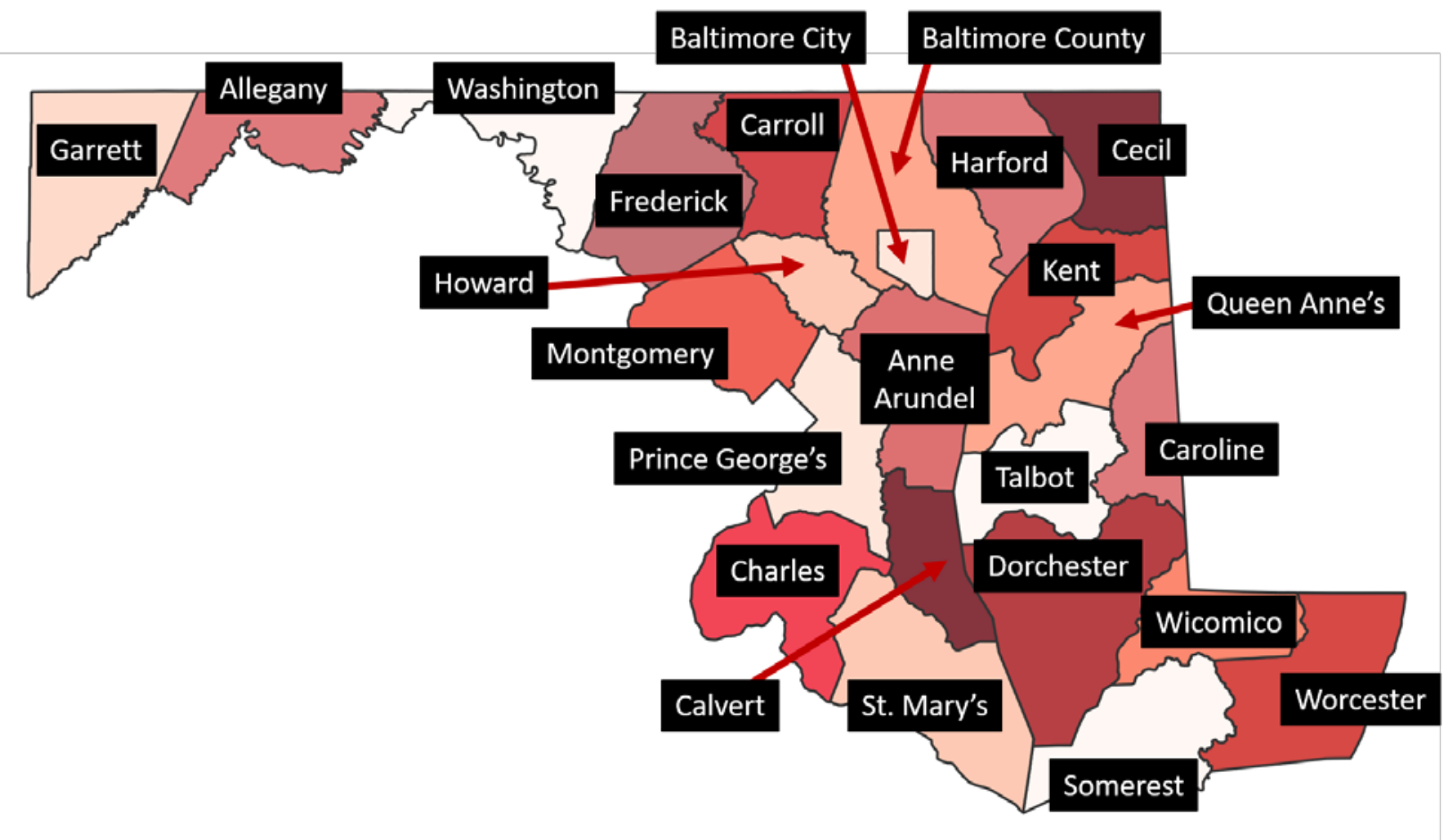

Figure 2. Maryland counties considered in this study

\subsection{Maryland Existing Light-Duty Vehicle Stock}

IHS data report 4.73 million LDVs registered in the state of Maryland at the end of 2016 (IHS Markit 2017). Figure 3 summarizes the makeup of these vehicles by fuel type. The proportions are consistent with national trends, with gasoline vehicles representing an overwhelming majority of the stock (89.3\%), and the remainder comprised E85 flexible fuel (6.4\%), diesel $(2.4 \%)$, and electrified powertrains $(2.0 \%)$.

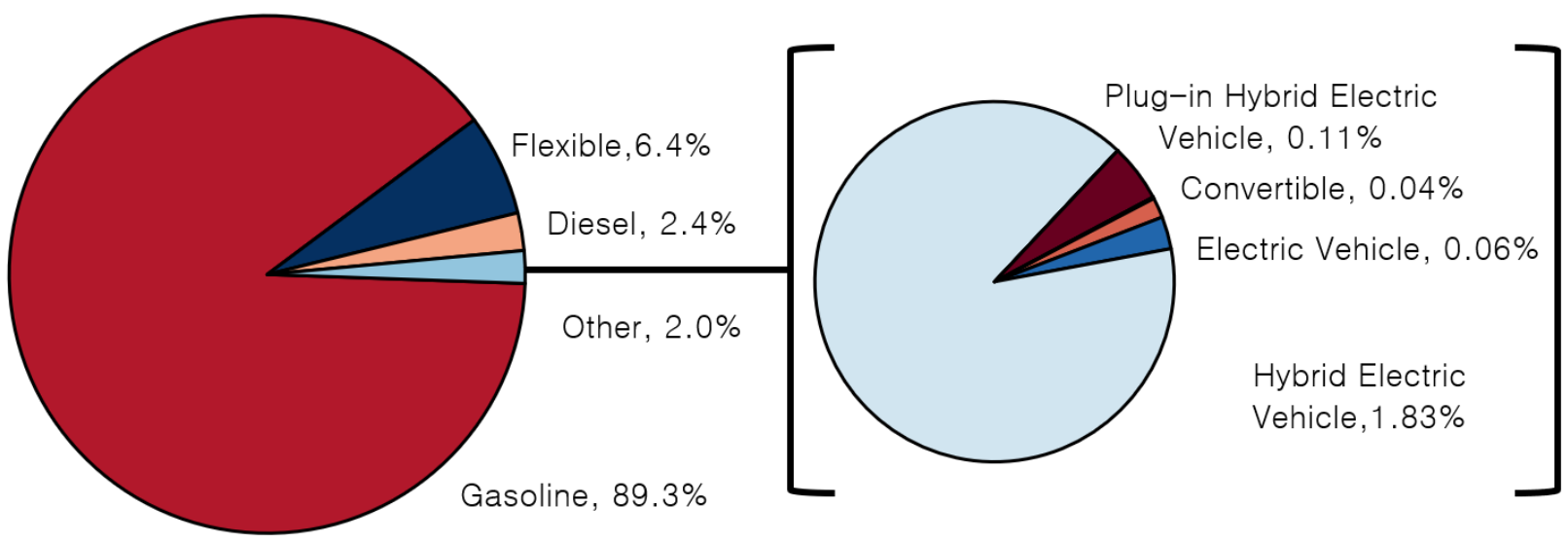

Figure 3. LDVs registered in Maryland as of the end of 2016 by fuel type

"Flexible" indicates E-85 capable vehicles, and "Convertible" indicates vehicles that were ready-made by the manufacturer for alternative fuel systems. Based on NREL analysis of IHS data (IHS 2017). 
IHS data are available throughout Maryland, enabling a spatial understanding of how the vehicles from Figure 3 are spread across the state. Figure 4 shows LDV registrations $(4.72$ million vehicles) by ZIP code. LDV registrations are understandably highest in areas with the largest populations (Baltimore and Washington, DC metropolitan areas, Anne Arundel County).

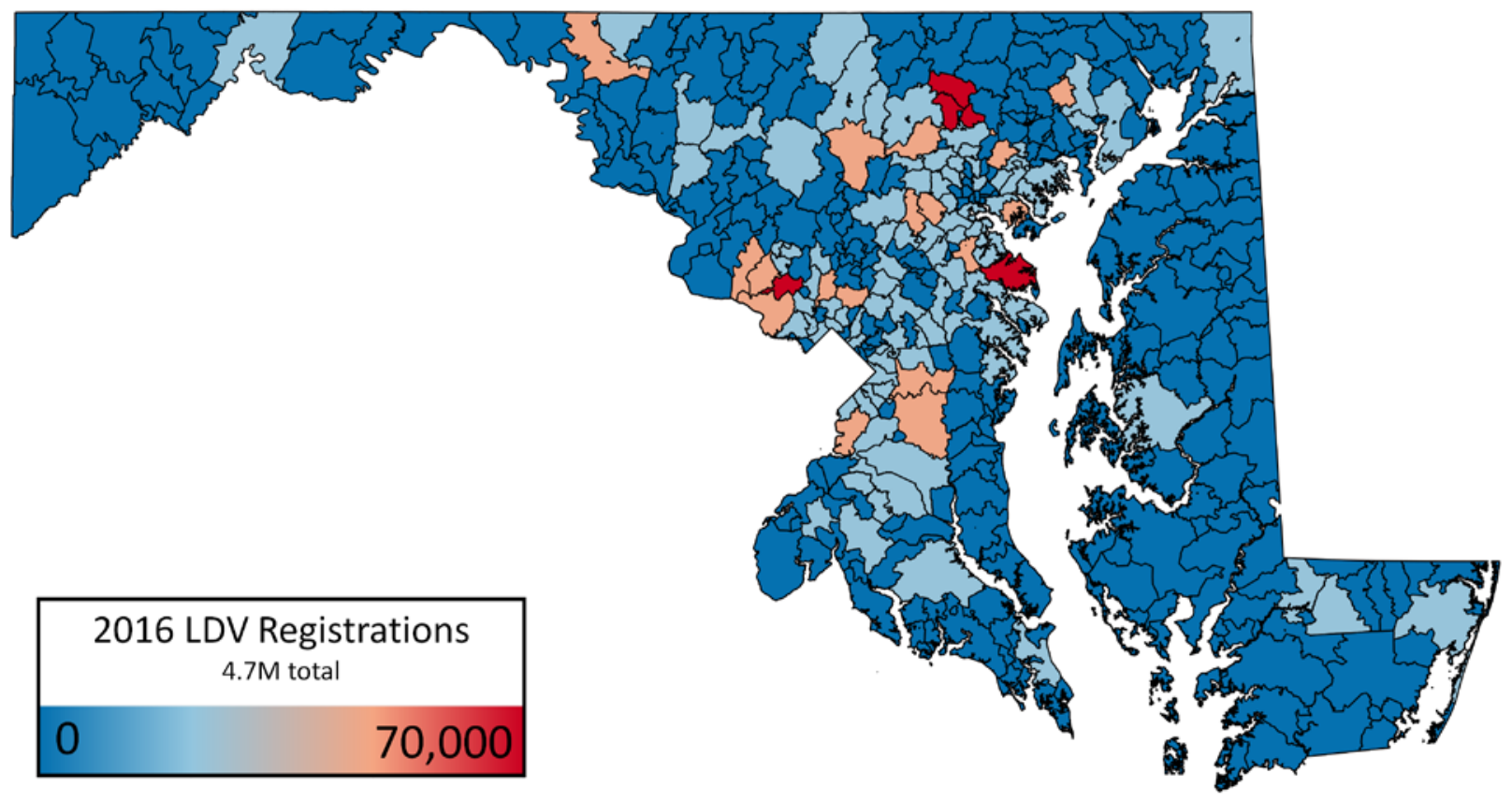

Figure 4. Maryland LDV registrations by ZIP code

IHS data report a total of 7,900 PEVs registered in Maryland at the end of 2016. The distributions by make/model and utility service territory are shown in Figure 5 and Table 2, respectively). More recent data provided by the Maryland Vehicle Administration shows a total of 10,175 PEVs registered in Maryland as of November 2017 with 57\% as plug-in hybrid electric vehicles (PHEVs) and $43 \%$ as BEVs indicating a recent surge in BEV registrations (relative to PHEV registrations).

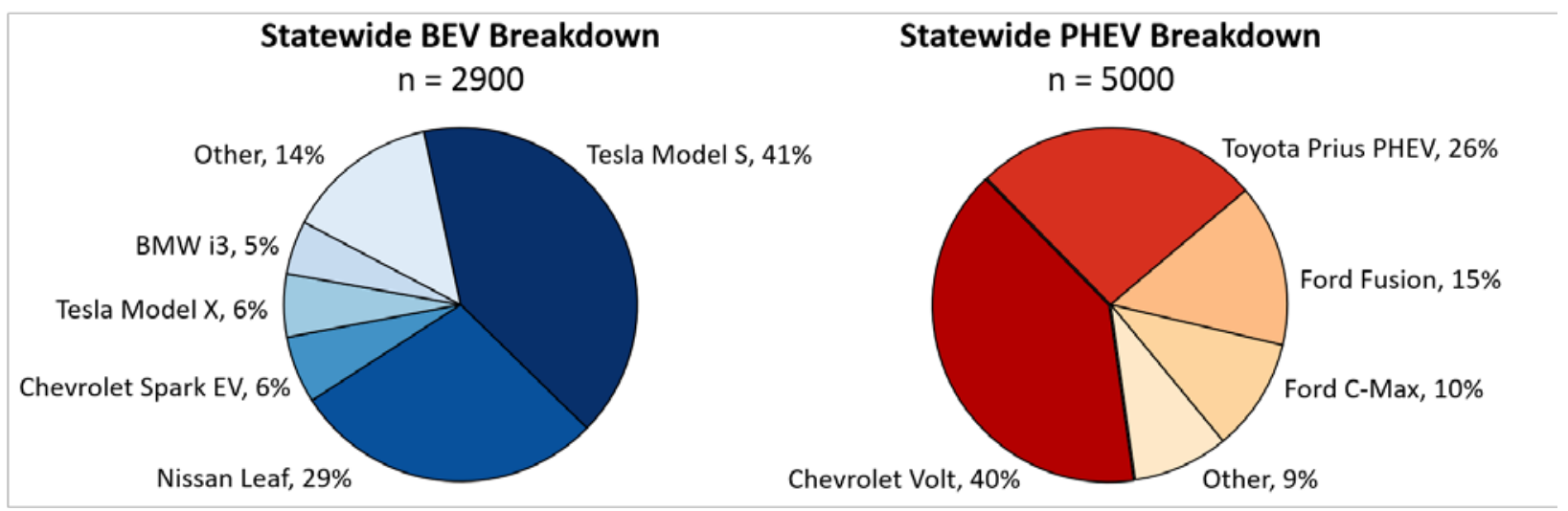

Figure 5. Maryland PEV registrations by make/model 
Table 2. Maryland PEV registrations by utility service territory

\begin{tabular}{lllll}
\hline Utility Service Territory & $\begin{array}{l}\text { BEV } \\
\text { Total }\end{array}$ & $\begin{array}{l}\text { PHEV } \\
\text { Total }\end{array}$ & $\begin{array}{l}\text { PEV } \\
\text { Total }\end{array}$ & \% BEV \\
\hline Baltimore Gas \& Electric Co & 1,320 & 2,720 & 4,050 & $33 \%$ \\
Potomac Electric Power Co & 1,190 & 1,380 & 2,570 & $46 \%$ \\
Potomac Edison Co & 210 & 480 & 690 & $31 \%$ \\
Southern Maryland Electric Coop Inc & 80 & 240 & 320 & $26 \%$ \\
Delmarva Power \& Light Co & 50 & 140 & 190 & $26 \%$ \\
Remaining Utilities & 20 & 70 & 90 & $23 \%$ \\
Total & $\mathbf{2 , 9 0 0}$ & $\mathbf{5 , 0 0 0}$ & $\mathbf{7 , 9 0 0}$ & \\
\cline { 1 - 3 } & & \multicolumn{2}{c}{}
\end{tabular}

\subsection{Maryland Existing Public Charging Networks}

Figure 6 shows the current charging infrastructure characterized by charger type, as recorded by the Alternative Fuels Data Center (AFDC) Station Locator (U.S. Department of Energy 2018). The type of charging available at each station is designated by the dot color, signifying either Level 1 (L1), Level 2 (L2), or direct current fast charge (DCFC). As of February 2018, Maryland had a total of 70 L1 plugs, 966 L2 plugs, and 172 DCFC plugs in the AFDC database. Existing stations are primarily located in the Baltimore and Washington D.C. metropolitan areas. The stations shown in Figure 6 are all publicly accessible; restricted stations at workplaces and residences are not shown given their limited access.

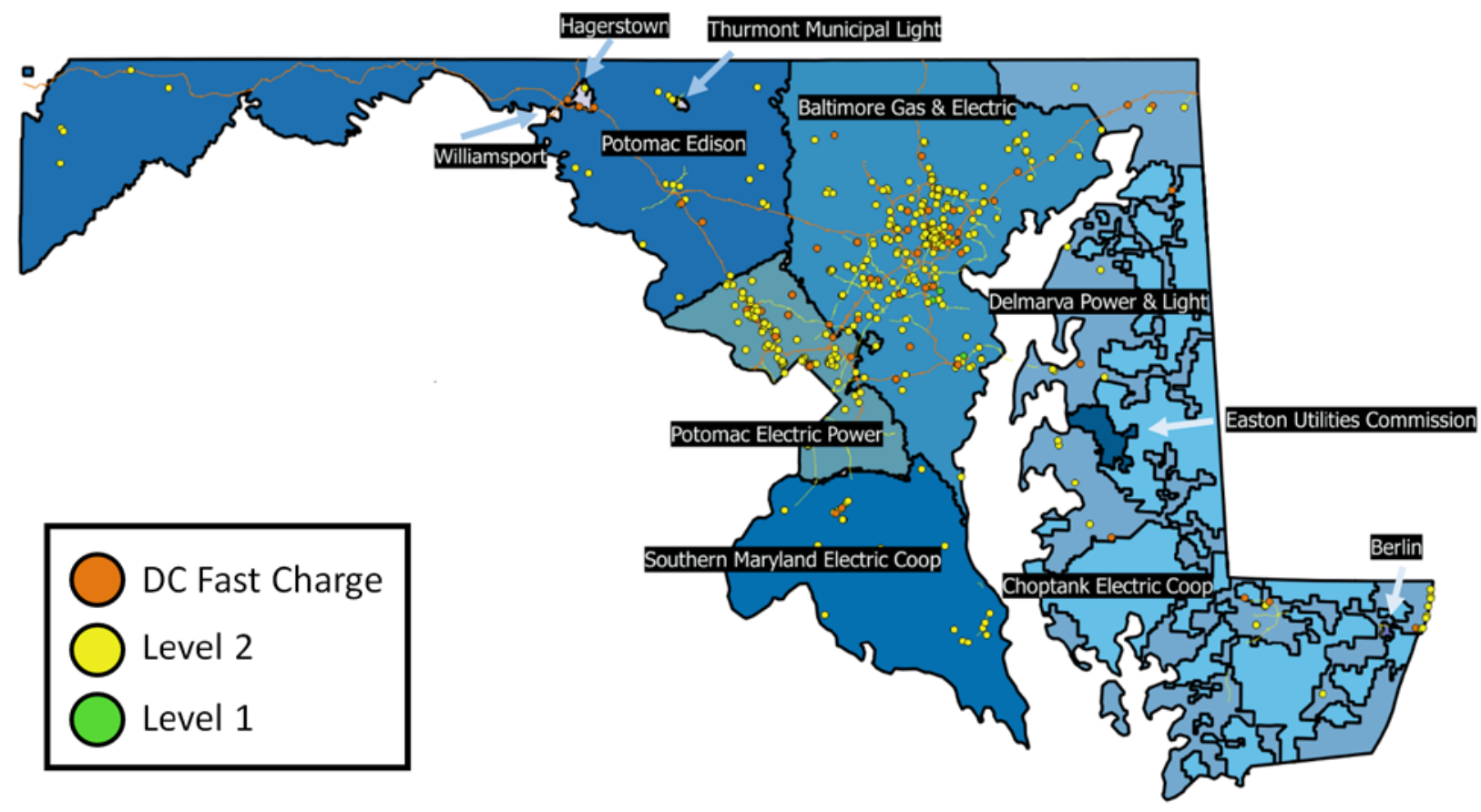

Figure 6. Existing public PEV charging infrastructure in Maryland 
Beyond listing the electric vehicle charging locations, the AFDC also reports the types and number of plugs at each station. Stations with a large number of plugs are able to service more vehicles at a given time. Figure 7 shows the number of publicly available electric vehicle charging plugs by type at the electric utility territory level as of February 2018. Baltimore Gas and Electric and Potomac Electric Power have the majority of the plugs in the state, which is expected given the large populations they serve and the current clustering of PEVs in these territories.

Finally, note that a given charging location may have multiple charging types. A station with plugs for Level 1 and Level 2 charging is counted as both types. Thus, the total number of Level 1, Level 2, and DCFC stations reported for the state of Maryland exceeds the number of charging locations. Please refer to Appendix A for raw plug and station counts at the utility service territory and county levels.

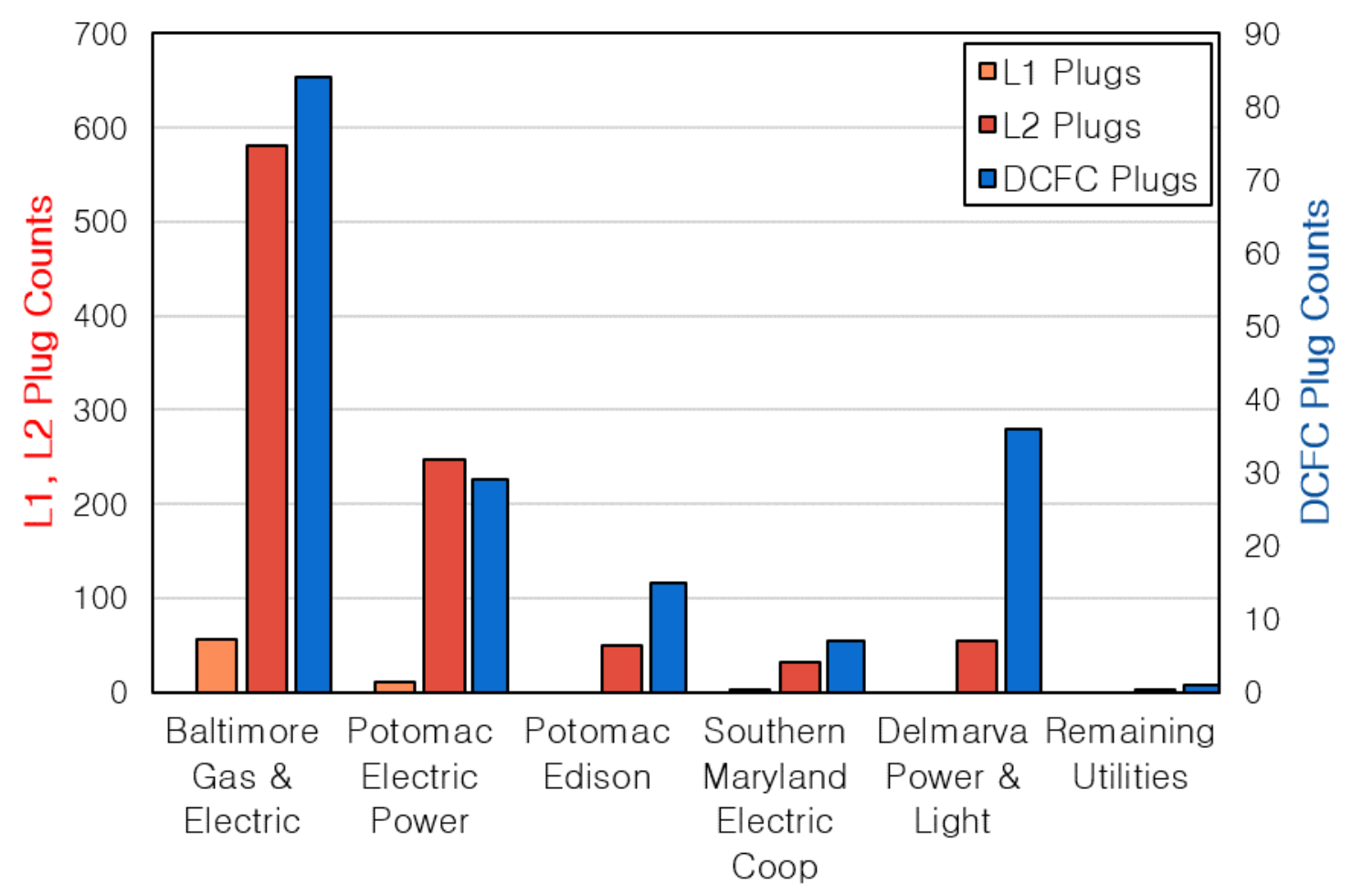

Figure 7. Existing public PEV charging plug counts in Maryland by electric utility 


\subsection{Baseline PEV Scenario: 300,000 in 2025}

Maryland's Zero Emission Vehicle goal of 300,000 PEVs by 2025 serves as the basis for the stock of vehicles that must be supported by the state's electric vehicle charging infrastructure for the baseline scenario in this report.

This analysis assumes that the Maryland 2025 PEV stock is distributed as: $30 \%$ PHEV20, 20\% PHEV50, 15\% BEV100, and 35\% BEV250. ${ }^{1}$ The effects of this stock assumption are explored using sensitivity analysis in Section 5.3. Prior research has suggested minimal need for describing vehicles beyond their powertrain type and electric range (SUVs, sedans, performance vehicles, etc.) for purposes of estimating PEV charging infrastructure requirements. For instance, Wood et al. (2017) found minimal sensitivity between the percentage of SUVs in the forecasted stock and the required electric vehicle charging infrastructure. However, differentiating between PEV powertrain type (BEV vs. PHEV) and electric range are shown to be important factors for the analysis.

While projections of the number and type of PEVs on the road in 2025 are valuable, projections of where the 300,000 PEVs might be distributed throughout the state are also important for forecasting infrastructure requirements. Attributing the forecasted number of PEVs in 2025 to current geographic clustering of PEVs is considered unreliable given the increase in PEV availability and the ongoing expansion of electric vehicle charging networks. Instead, existing hybrid electric vehicle (HEV) registrations are used to predict the spatial distribution of PEVs in 2025. Spatial distribution of existing HEVs by ZIP code is shown in Figure 8. Prior research has shown that areas with large number of HEVs are correlated with adoption of PEVs (Wood et al. 2018).

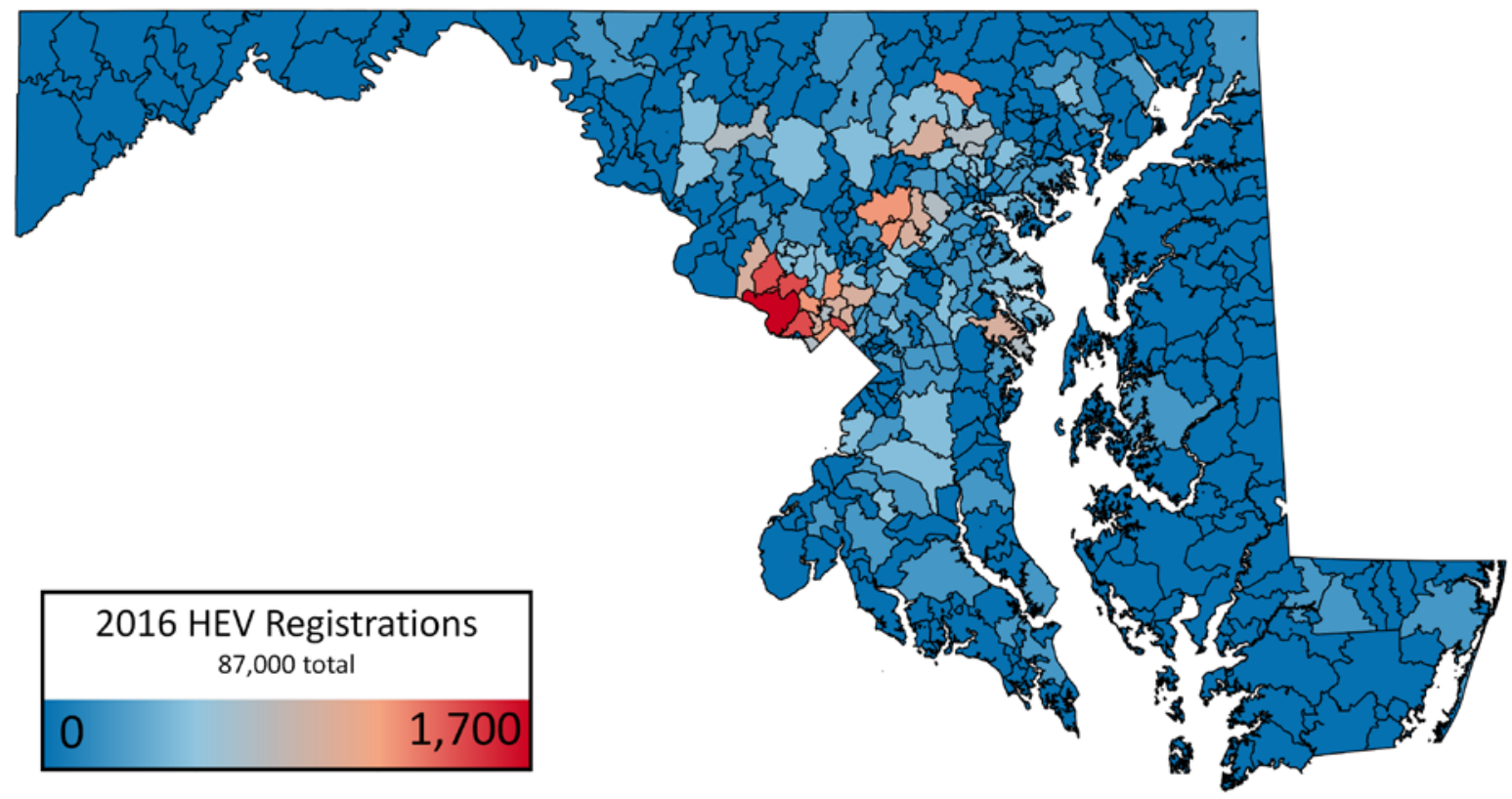

Figure 8. Maryland combined PEV and HEV registrations by ZIP code.

\footnotetext{
${ }^{1}$ BEV xxx indicates a BEV with a range of $x x x$ miles. PHEVxx indicates a PHEV with a range of $x x$ miles.
} 
While most present day PEV charging takes place at residential locations, high density parking and housing environments present challenges for urban PEV owners, particularly those living in multi-unit dwellings (MUDs). This analysis accounts for the share of charging taking place at residential locations to estimate demand for charging infrastructure at work and public locations. As such, assumptions must be made regarding the number of PEVs adopted by residents of MUDs. This analysis uses data from the 2016 American Community Survey to quantify household ownership and residence type information (summarized in Appendix B) (American Community Survey 2016). Assumptions regarding potential availability of residential charging at each household type are applied considering renters and individuals in large complexes having limited ability to park and charge their vehicle in a consistent location. These individuals would presumably be reliant on workplace charging and public networks to satisfy most of charging needs. This combination of housing data and assumptions regarding availability of home charging results in $70 \%$ of 2025 PEVs having access to home charging, and $30 \%$ classified in the remainder of the report as MUDs without access to home charging.

Table 3 describes the assumed spatial disaggregation of 2025 PEVs by type at the utility territory level (see Appendix C for a similar breakdown at the county level).

Table 3. Projected 2025 PEV Counts by Type and Utility Service Territory

\begin{tabular}{lllllll}
\hline Utility Service Territory & MUD (\%) & PHEV20 & PHEV50 & BEV100 & BEV250 & Total \\
\hline Baltimore Gas \& Electric & 30 & 42,678 & 28,452 & 21,339 & 49,791 & 142,260 \\
Potomac Electric Power & 36 & 29,090 & 19,393 & 14,545 & 33,938 & 96,966 \\
Potomac Edison & 20 & 7,494 & 4,996 & 3,747 & 8,743 & 24,980 \\
Southern Maryland Electric Coop & 13 & 5,435 & 3,624 & 2,718 & 6,341 & 18,118 \\
Delmarva Power \& Light & 17 & 3,503 & 2,335 & 1,751 & 4,087 & 11,676 \\
Remaining Utilities & 12 & 1,800 & 1,200 & 900 & 2,100 & 6,000 \\
Total & 30 & 90,000 & 60,000 & 45,000 & 105,000 & 300,000 \\
\hline
\end{tabular}




\section{INRIX GPS Travel Trajectories}

Travel patterns are one of the main drivers of PEV charging infrastructure requirements. To properly model PEV charging infrastructure requirements in Maryland, NREL acquired individual GPS travel trajectories from INRIX, a commercial traffic/mapping provider that works with automotive manufacturers, commercial fleet operators, mobile companies, and state and local transportation departments to provide real-time traffic and mobility analytics. INRIX products are based on anonymized GPS data collected from hundreds of millions of devices.

\subsection{Data Summary and Visualization}

The INRIX data set used in this study includes all GPS travel trajectories (mode imputed as driving trips by INRIX) that intersected the Maryland region during a four-month sample from 2015. Each travel trajectory features trip-level data such as start and end times and GPS coordinates (including origin, destination, and intermediate waypoints). The data set contains a total of 5.6 million unique device identifiers, 20 million trips, 426 million miles of driving, and over 1.3 billion GPS waypoints. Figure 9 shows a destination heatmap of the INRIX data set for trips ending in Maryland. Trips starting in Maryland and ending out of state are considered in the infrastructure analysis but are not included in the figure.

\subsection{Down Sampling and Data Processing}

Prior to using the INRIX travel data subset in PEV driving/charging simulations, several data processing steps were completed, including:

- Eliminating all travel data not originating from light-duty vehicles

- Removing the first and last vehicle-day for each device identifier (to remove incomplete travel days)

- Editing trip origins to ensure consistency with previous destination in the trip chain

- Computing trip driving distance based on adjusted origin, waypoints, and original destination

- Assessing trip destinations (i.e., home and workplace location for each device identifier based on destination frequency and time of day over multiple travel days)

- Implementing spatial joins on county, utility service territory, and land use data layers.

These processing steps are consistent with measures taken by NREL on a similar INRIX data set from Columbus, Ohio (Wood et al. 2018). Down sampling and data processing for all LDV trips in the INRIX travel data set remove approximately $90 \%$ of the original data, reducing the data set used in this study to approximately 440,000 full travel days, 1.4 million trips, and 20 million miles of driving (a sufficiently large data set for purposes of estimating charging infrastructure requirements for the 300,000 PEVs considered in this study). 


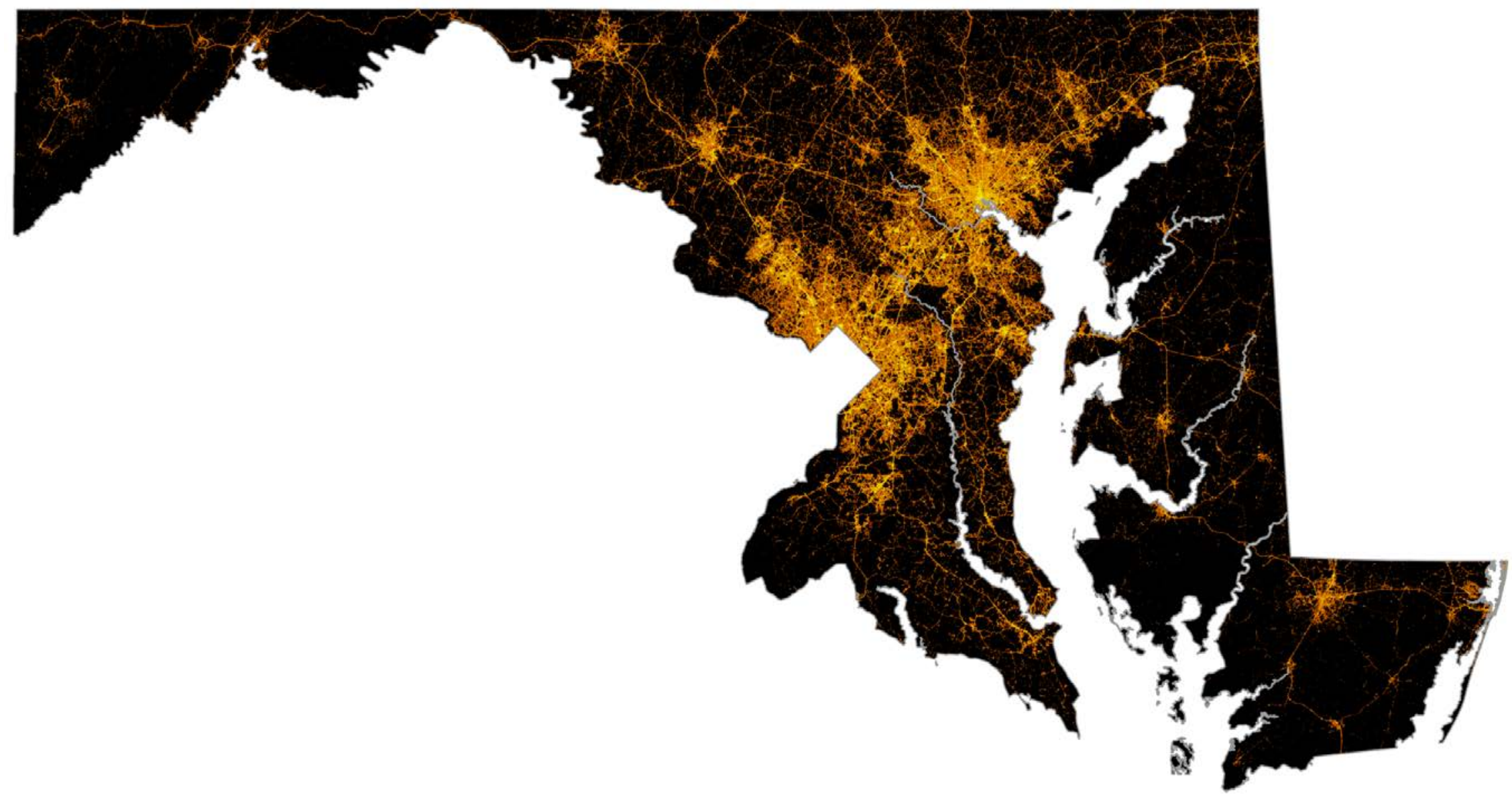

Figure 9. Trip-destination frequency map derived from the INRIX travel data set 


\subsection{Data Validation}

The processed INRIX data for Maryland are compared to other large-scale GPS travel datasets to check for consistency and compare trends. Figure 10 shows the distribution of daily vehicle miles traveled (VMT) from the processed INRIX travel data and comparable distributions from the GPS portion of the 2012 California Household Travel Survey (CHTS) and an additional processed GPS dataset from INRIX describing light duty vehicle travel in Columbus Ohio during 2016.The processed INRIX travel data displays a longer daily distance driven compared to the travel datasets in Columbus and California, with up to a $10 \%$ deviation in the cumulative distribution of daily VMT (impact of daily driving distance on charging infrastructure requirements is explored as a sensitivity in Section 5.3). One explanation for the difference in daily VMT is the differing levels of urbanization within the regions shown; the 2016 INRIX Columbus dataset is almost exclusively urban driving while the 2012 CHTS and 2015 INRIX contain increasingly larger portions of rural travel. Several iterations of the National Highway Travel Survey support the role urbanization plays on reducing driving. Table 4 contains results comparing the daily VMT calculated in urban and rural regions over a period of approximately 20 years (Santos et al. 2011).

Table 4. Comparison of daily VMT between urban and rural areas

\begin{tabular}{llll}
\hline Year & Mean Urban VMT & Mean Rural VMT & Percent Difference \\
\hline 1990 NPTS & 22.41 & 29.61 & $+32 \%$ \\
1995 NPTS & 25.00 & 34.63 & $+39 \%$ \\
2001 NHTS & 27.30 & 37.56 & $+38 \%$ \\
2009 NHTS & 23.14 & 34.18 & $+48 \%$
\end{tabular}




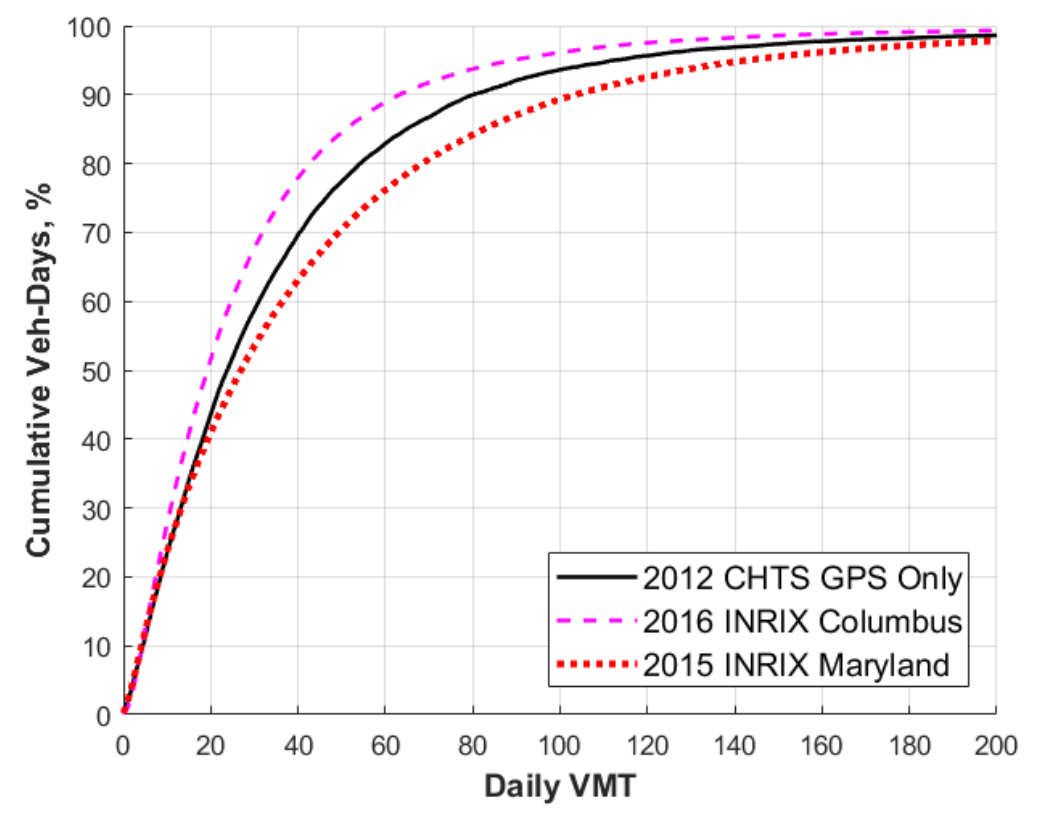

Figure 10. Distribution of daily VMT from processed INRIX data and additional GPS datasets.

Similarly, Figure 11 shows a comparison of trip counts by time of day from the processed 2015 INRIX travel data for Maryland and comparable data from 2012 CHTS and 2016 INRIX Columbus. All three data sets show a similar pattern of morning/afternoon peaks with trip counts tapering off in the early evening and few trips taking place during the night.

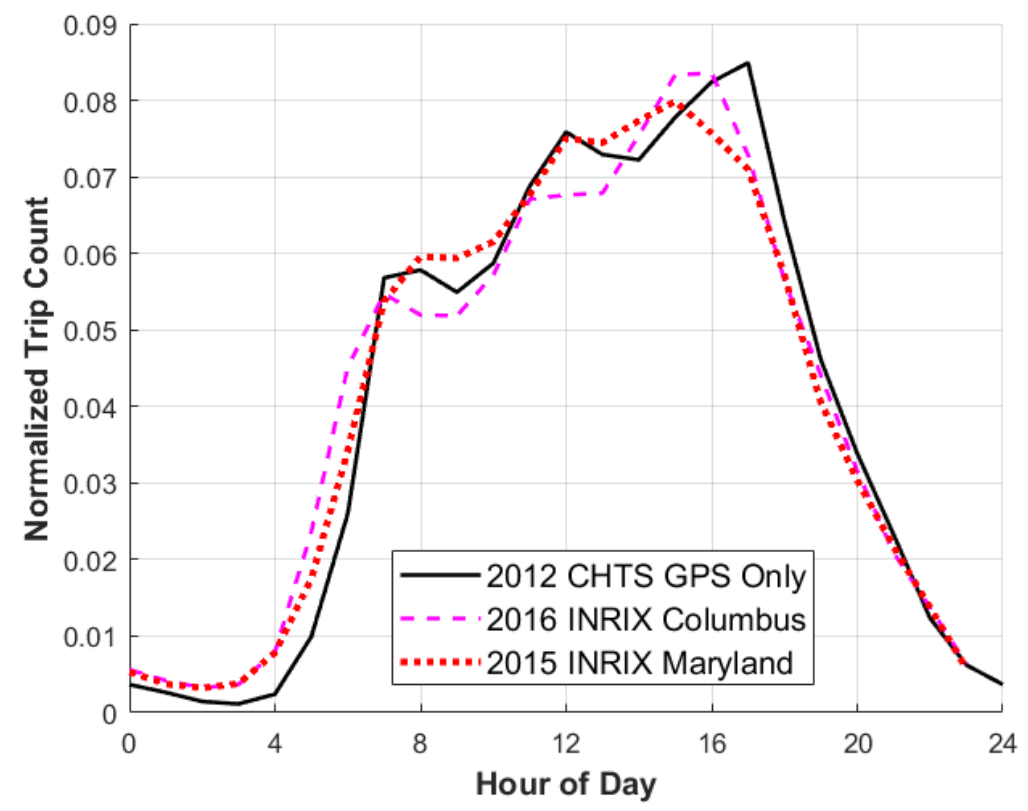

Figure 11. Distribution of trips by time of day from processed INRIX data and additional GPS datasets. 


\section{EVI-Pro Methodology}

NREL's EVI-Pro model was used with the INRIX data to simulate PEV driving and charging behavior and estimate infrastructure requirements. Section 4.1 describes the EVI-Pro model, Section 4.2 reviews PEV attributes used for baseline simulations in this study, and Section 4.3 reviews charging infrastructure attributes used for baseline simulations in this study.

\subsection{EVI-Pro Model Description}

In collaboration with the California Energy Commission, NREL developed EVI-Pro to estimate requirements for charging infrastructure to support consumer adoption of PEVs. EVI-Pro uses PEV market projections and real-world travel data from mass market consumers to estimate future requirements for residential, workplace, and public charging under a variety of scenarios. Outputs of the model include: anticipating spatial/temporal consumer demand for charging accounting for the impact of single-unit dwelling (SUD) and MUD residency, weekday/weekend travel behavior, and regional differences in travel behavior and vehicle adoption. A graphical representation of the input/output relationships in EVI-Pro is shown in Figure 12, including the primary processing steps in the model: 1) conducting individual PEV driving/charging simulations over real-world 24-hour driving days, 2) spatial-temporal post processing of individual charging events to derive ratios of charging plugs to PEVs, and 3) scaling said ratios per a PEV stock goal or projection.

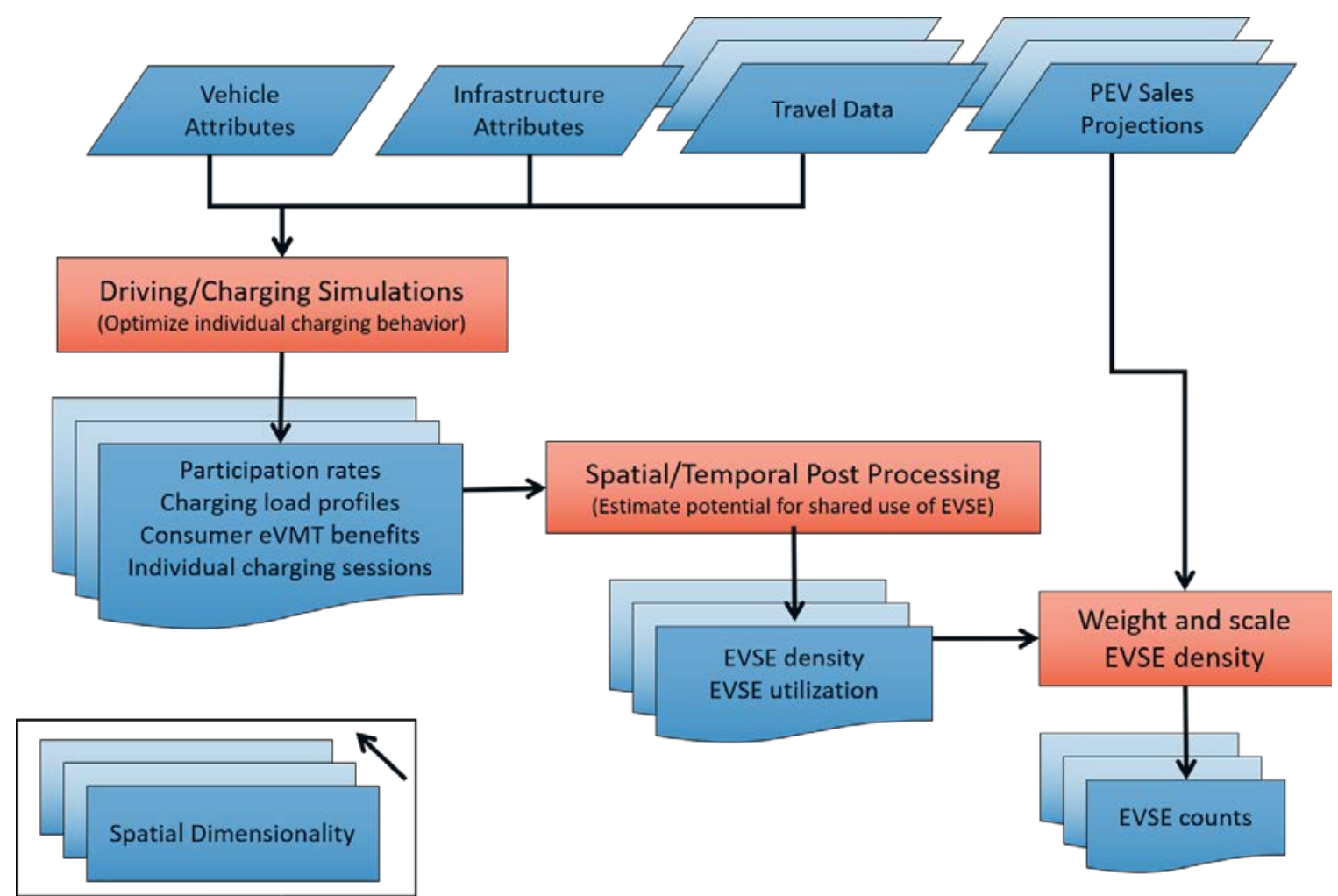

Figure 12. Graphical representation of inputs/outputs and data flow in EVI-Pro

eVMT: electric vehicle miles traveled EVSE: electric vehicle supply equipment 
EVI-Pro uses a "bottom-up" approach to estimate PEV charging requirements with the fundamental element of 24-hour daily driving schedules from real-world vehicles. While these driving schedules are typically sourced from gasoline vehicles, EVI-Pro simulates each driving day as though it were attempted in a PEV. By applying real-world travel data from gasoline vehicles to simulated PEVs, EVI-Pro attempts to estimate charging solutions that enable future PEVs to serve as a direct replacement for the gasoline vehicles that represent the present-day majority of the LDV fleet.

Charging solutions to complete individual days of driving are estimated by identifying charging opportunities that are consumer-oriented for both convenience and cost. Convenience is achieved by simulating charging events as only taking place during dwell times present in the original travel data. The EVI-Pro method implies that the mainstream PEV drivers will have a low tolerance for altering travel behavior on a regular basis to accommodate charging their vehicle. When the price of charging is equivalent for two or more locations, EVI-Pro assumes that consumers prefer to charge at locations with long dwell times. This approach implies a greater energy transfer per charging event and helps to minimize the number of charging events per day. Simulated consumers in EVI-Pro are modeled as being economically efficient, preferring to charge their vehicles at locations that help minimize charging costs. Simulated consumers are provided with charging cost information and the energy needed to complete their next trip, so each simulated PEV driver can decide whether a charging event is needed at their current location. Once feasible charging solutions are identified, the model further iterates through driving/charging events until the battery state of charge at the start and end of the simulated day are consistent.

In addition to the objective of minimizing cost, simulated consumers are also subject to constraints on battery state of charge. For each simulated driving day in EVI-Pro, BEVs are required to maintain battery state of charge above a pre-defined level, defined as a reasonable proxy for minimizing range anxiety (a 20 -mile range tolerance is assumed in this study). Since PHEVs can operate with a depleted battery in charge-sustaining mode, EVI-Pro does not place a constraint on the minimum allowable state of charge for PHEVs, but instead attempts to maximize electric VMT and minimize gasoline consumption.

While the individual driving and charging simulations determine the number of vehicles that utilize each charger type, the amount of infrastructure required to satisfy charging demand is dependent on the spatial-temporal coincidence of charging. For example, consider a fixed number of charging events at public L2 chargers. If these charging events take place at the same location and are uniformly distributed throughout the day, a minimal amount of infrastructure can meet the demand (corresponding to the high utilization of a small number of chargers). Conversely, if the same number of charging events take place in isolated locations all at the same time, a much larger amount of infrastructure is required (corresponding to the low utilization of a large number of chargers). EVI-Pro calculates spatial-temporal coincidence of simulated charging events by geographically aggregating charging sessions and allocating sufficient charging capacity (plugs) to prevent queuing at each individual charging location (stations). 


\subsection{Simulated PEV Attributes}

The vehicle attributes specified in EVI-Pro include the electric range (in miles), vehicle drive efficiency (watthours-per-mile), minimum range tolerance (in miles), onboard charger efficiency, and maximum alternating current charging power. Vehicle energy consumption, which is the main driver of charging requirements, is computed based on highly resolved speed profiles for each different model type and accounts for temperature effects on fuel economy (Wood et al. 2017). Table 4 summarizes the attributes of the PEVs considered in this report.

Table 5. Modeled PEV Attributes

\begin{tabular}{|c|c|c|c|c|}
\hline & PHEV20 & PHEV50 & BEV100 & BEV250 \\
\hline $\begin{array}{l}\text { Nominal Electric Driving } \\
\text { Range, mi }\end{array}$ & 20 & 50 & 100 & 250 \\
\hline $\begin{array}{l}\text { Nominal Energy } \\
\text { Consumption, Wh/mi }\end{array}$ & 325 & 325 & 325 & 325 \\
\hline $\begin{array}{l}\text { Minimum Range } \\
\text { Tolerance, mi }\end{array}$ & 0 & 0 & 20 & 20 \\
\hline $\begin{array}{l}\text { Onboard Charger } \\
\text { Efficiency }\end{array}$ & $90 \%$ & $90 \%$ & $90 \%$ & $90 \%$ \\
\hline $\begin{array}{l}\text { Maximum AC Charging } \\
\text { Power, kW }\end{array}$ & 3.6 & 3.6 & 20 & 20 \\
\hline
\end{tabular}

AC: alternating current

$B E V x x$ : battery electric vehicle with a range of $x x$ miles kW: kilowatt

PHEVxx: plug-in hybrid electric vehicle with a range of $x x$ miles

Wh: watt-hour 


\subsection{Simulated Infrastructure Attributes}

Charging infrastructure is segmented by location type as home (SUD or MUD), workplace, and public (any destination not classified as either a home or work destination). For each location type, up to three charging power levels are available (L1, L2, DCFC). For all simulated charging opportunities, a minimum dwell time for the driver to consider plugging in (at all location types, including home) is also be specified (minimum dwell time of 2 hours for L1/L2 opportunities, 30 minutes for DCFC opportunities), though simulated consumers may not plug in at every opportunity depending on their daily charging needs.

Consumer charging preferences are implemented in EVI-Pro to simulate selection of charging opportunities for individual travel days. This analysis considers a baseline scenario where residential charging is preferred by consumers (if available) with workplace charging, public L2 charging, and DCFC used to fill gaps in daily charging needs (in that order). Sensitivities on consumer charging preferences are explored in Section 5.3.

Several scenarios are simulated for each consumer to cover a broad range of possible charging options and capture their impact on PEV charging, infrastructure requirements, and resulting electric load. A matrix of all charging options considered is shown in Table 5. The effective DCFC charge rate is adjusted for temperature effects as well as charge duration, assuming that charging power tapers as battery state of charge approaches high levels (Wood et al. 2017).

Table 6. Charging Options Available to Consumers in EVI-Pro

\begin{tabular}{|c|c|c|c|}
\hline Location & Level & Power & Comment \\
\hline \multirow[t]{2}{*}{ Home } & L1 & 1.4 kW & \\
\hline & L2 & $3.6 \mathrm{~kW}$ & $\begin{array}{l}\text { BEVs simulated with higher L2 power to enable full } \\
\text { overnight charge }\end{array}$ \\
\hline Work & L2 & $6.2 \mathrm{~kW}$ & $\begin{array}{l}\text { PHEV on-board charger limits maximum power to } \\
3.6 \mathrm{~kW} \text { in EVI-Pro }\end{array}$ \\
\hline \multirow[t]{2}{*}{ Public } & L2 & $6.2 \mathrm{~kW}$ & $\begin{array}{l}\text { PHEV on-board charger limits maximum power to } \\
3.6 \mathrm{~kW} \text { in EVI-Pro }\end{array}$ \\
\hline & DCFC & 50 kW & $\begin{array}{l}\text { BEVs only; charge rate tapers off at high state of } \\
\text { charge }\end{array}$ \\
\hline
\end{tabular}

$\mathrm{L} 1=$ level 1 charging station

L2 = level 2 charging station 


\section{Simulation Results}

Section 5.1 reports infrastructure requirements for a baseline scenario considering 300,000 PEVs on the road in Maryland by 2025. Section 5.2 reviews the potential for utilizing L1 and L2 plugs at workplaces. Sensitivity analyses around some of the key assumptions are explored in Section 5.3. Several simulated load profiles are reviewed in Section 5.4 with a discussion on how PEV selection and consumer charging behavior influence simulated electrical loads from PEV charging. Finally, the simulated load profiles are explored further with an investigation into time of use pricing in Section 5.5.

\subsection{Baseline Results}

Statewide EVI-Pro simulations were run assuming 300,000 PEVs on the road in Maryland by 2025. Simulations utilized 24-hour driving days derived from 426 million miles of real-world driving data provided by INRIX. Use of this driving data (collected during 2015) for PEV simulations implicitly assumes that future Maryland drivers will attempt to utilize PEVs in a manner consistent with present-day vehicles. Furthermore, EVI-Pro assumes a partial level of support for non-residential PHEV charging by residents with consistent access to residential charging (under the assumption that half of these drivers will not seek to charge away from home as a matter of convenience). A 50/50 split was assumed between PHEVs and BEVs. A significant percent of overall required charging infrastructure was driven by the assumption that $30 \%$ of PEVs statewide will be owned by individuals without consistent access to residential charging. These individuals (broadly defined as MUD residents) are thus reliant on workplace charging and public networks for most of their daily charging needs.

Baseline results for Maryland are presented in Table 6 by utility service territory and charger type. Please refer to Appendix D for baseline results at the county level. A statewide total of approximately 27,000 non-residential L2 plugs and 1,000 DCFC plugs are estimated as necessary for supporting future consumer demand for PEV charging. Note that these estimates include a significant amount of residential charging. Despite simulating 30\% of PEVs as not having access to residential charging, $66 \%$ of statewide charging is simulated as taking place at home. The percentage of residential charging increases to approximately $90 \%$ for the $70 \%$ of PEVs assumed to have access to charging at their home location).

Table 7. Estimated Plug Counts by Utility Service Territory

\begin{tabular}{llll}
\hline Utility Service Territory & Work L2 & Public L2 & DCFC \\
\hline Baltimore Gas \& Electric & 8,564 & 4,568 & 486 \\
Potomac Electric Power & 5,946 & 3,059 & 221 \\
Potomac Edison & 1,376 & 719 & 139 \\
Southern Maryland Electric Coop & 649 & 416 & 58 \\
Delmarva Power \& Light & 556 & 377 & 87 \\
Remaining Utilities & 302 & 160 & 43 \\
Total & 17,393 & 9,299 & 1,034 \\
\hline
\end{tabular}


Despite the fact that L2 charging outnumbers DCFC by a factor of 26 in these estimates, readers are cautioned against regarding L2 infrastructure as more valuable than DCFC, as this is not necessarily true. Fundamentally, each type of charging infrastructure plays a unique role in supporting the PEV market. EVI-Pro simulations typically provide the majority of L2 charging to support increased electric VMT of PHEVs, which are simulated as not being capable of fast charging. As PHEVs are equipped with a gasoline backup for quickly replenishing driving range, non-residential L2 charging can be considered a relatively soft infrastructure requirement. DCFC infrastructure on the other hand is a relatively hard requirement for BEV drivers who have no other alternative for quickly replenishing driving range. In fact, the mere presence of DCFC stations may be required to provide BEV drivers with a safety net against infamous range anxiety concerns.

Estimated L2 requirements at workplaces are nearly twice as great compared to public locations. EVI-Pro finds that commuting distances to workplaces and dwell times for vehicles parked at workplaces on average provide superior charging opportunities for supplementing residential charging for residents of SUDs and for serving as the primarily charging solution for residents of MUDs. In additional to favorable travel pattern characteristics, workplace charging results are bolstered by the EVI-Pro baseline assumption that consumers prefer L2 charging at work as opposed to public locations when both alternatives are viable options. The impact of this assumption is tested using sensitivity analysis in Section 5.2.

Overall, the baseline estimate implies that significant growth in Maryland's current charging network is necessary to satisfy charging demand from future PEVs.

\subsection{Work Charger Availability Adjustment}

The baseline case assumes exclusive availability of L2 chargers at work locations. Omission of L1 plugs at workplaces is based on stakeholder requirements (in Maryland and elsewhere) that chargers have smart and networked capabilities for dynamic load management and billing purposes. Additionally, the use of L1 chargers also makes metering and billing more challenging at work locations. As the existing market for chargers with these features has been dominated by L2 units, L1 is manually restricted in the baseline scenario. However, a deviation from the baseline set of assumptions was explored in which workplace charging options included L1 charging in addition to L2 charging. For many travel days, the choice between a L1 and L2 plug did not change the amount of energy consumed at work; workplace charging frequently consists of long dwell times supplemented by charging at residencies. In fact, nearly $75 \%$ of workplace charging events simulated in the baseline case were found to be satisfied by L1 charging.

Despite the large majority of workplace charging events which can be satisfied through L1 plugs, these plugs produce only $35 \%$ of the energy dispensed at workplaces. L1 charging events at work are limited to vehicles with smaller energy needs, while L2 charging events require high power throughout the majority of workplace dwell times (MUD residents depending on workplace charging, for instance).

\subsection{Sensitivity Analysis}

The 2025 statewide charging infrastructure values presented in Section 5.1 are a reasonable estimate built upon a large data set of real-world driving patterns, a modeling framework 
predicated on rational consumer behavior, and sound engineering judgment regarding technology development. However, a technical problem this vast leaves much room for uncertainty. To better understand how baseline estimates are affected by various assumptions, a parametric sensitivity analysis is conducted varying individual parameters one at a time (in both directions where possible). Sensitivity analysis results are presented in Figure 13 for non-residential L2 (work and public) and DCFC as relative to the baseline results previously presented.

By far the largest sensitivity for non-residential L2 was simply the number of PEVs on the road. Varying this parameter induced an approximate $\pm 67 \%$ swing in both non-residential L2 and DCFC estimates. This is not necessarily a surprising result as this input parameter was explored quite aggressively using a $\pm 200,000$ swing in the number of PEVs on the road in Maryland by 2025.

In addition to the number of PEVs on the road, the types of PEVs that get adopted also have a significant impact on charging infrastructure requirements. The "PHEV:BEV" and "Range Preference" sensitivities manipulate the mix of PEVs while holding the statewide total constant. PHEV:BEV ratio is swept from 4:1 (80\% PHEV) to $1: 4(80 \% \mathrm{BEV})$ and results in a $\pm 16 \%$ swing for non-residential L2 and a $\pm 60 \%$ for DCFC. Range preference is swept from a "short" setting (comprising 50\% PHEV20 and 50\% BEV100) to a "long" setting (comprising 50\% PHEV50 and $50 \%$ BEV250). This sensitivity results in a $\pm 10 \%$ swing in non-residential L2 and a $-14 \%$ to $+32 \%$ swing for DCFC. These two sensitivities directly relate PEV attributes to infrastructure requirements. For instance, PHEVs are not simulated as DCFC capable; thus, increasing PHEV shares decreased DCFC demand and increased L2 demand. Similarly, PEVs with longer electric driving ranges generally decrease infrastructure requirements as they can accommodate most of their charging needs with an overnight charge at home.

Impacts of fast charging technology development are prominent in the sensitivity analysis. Research enabling high power fast charging (up to $400 \mathrm{~kW}$ ) is currently an area of great interest as an enabling technology for BEV ownership. The "DCFC Power Level" sensitivity explores the relationship between high-power fast charging and infrastructure requirements. This sensitivity is explored from a $50-\mathrm{kW}$ baseline to a $400-\mathrm{kW}$ scenario where the charge acceptance rate of BEV battery packs is assumed to scale accordingly with the nominal DCFC power rating. Increasing fast charge power from $50 \mathrm{~kW}$ to $400 \mathrm{~kW}$ is simulated as decreasing DCFC plug requirements by $71 \%$. While this result is revealing, some caveats should be made. First, it must be acknowledged that this sensitivity is explored within the context of fixed demand. This means that faster charging times translate directly to faster turnover times for individual charging events at DCFC stations, which results in lower plug count requirements at each simulated DCFC station. Additionally, it is reasonable to assume that successful deployment of 400-kW fast charging stations would increase sales of high-power fast charge capable BEVs. While this feedback loop is readily acknowledged, it is not explicitly considered in this parametric sensitivity analysis.

Consumer preference for fast charging is explicitly considered in the "DCFC Preference" scenario (though not directly coupled to market success of long-range BEVs or high-power fast charging in the sensitivity analysis). This scenario assumes that consumers place sufficient value on the convenience of fast charging such that they seek it out ahead of L2 for public charging opportunities; however, residential and workplace charging remain preferred to fast charging. 
This sensitivity results in a 13\% decrease in demand for non-residential L2 and a $28 \%$ increase in demand for fast charging.

Similarly, the "Workplace Preference" scenario manipulates consumer charging preferences such that public charging (both L2 and DCFC) is preferred above workplace charging. To some degree the non-residential L2 effects of this scenario are offsetting (demand for workplace L2 decreases and public L2 increases); however, on net non-residential L2 demand decreases by approximately $14 \%$. Conversely, DCFC demand experiences a $11 \%$ increase, essentially covering the lost demand for workplace charging that cannot be met by public L2.

While not impacting consumer demand for DCFC, the "PHEV Support" sensitivity has a dramatic impact on consumer demand for non-residential L2. Consumer demand for nonresidential L2 infrastructure decreases by $57 \%$ in the "No Support" scenario and increases by $43 \%$ in the "Full Support" scenario. These scenarios represent extreme conditions regarding demand for non-residential charging by PHEV owners with access to home charging (a segment of consumers with relatively soft demand for charging away from home).

The role of MUDs is of unique importance to estimating charging infrastructure requirements in Maryland given the state's relatively high urban population. Recall that the baseline scenario in this analysis assumes $30 \%$ of PEVs are adopted by individuals without consistent access to residential charging (broadly referred to as MUD residents in this report). The "MUD PEV Share" sensitivity explores the impact of decreasing this assumption from $30 \%$ to $0 \%$, which results in decreases for non-residential L2 and DCFC demand of $22 \%$ and $37 \%$, respectively. Given that MUDs are simulated in the baseline as not having access to home charging, this result is relatively intuitive. It is also worth noting that this sensitivity is largely consistent with a scenario in which MUD charging access at home is enabled (non-residential infrastructure requirements for PEVs with access to home charging are roughly independent of residence type).

Recall from Figure 10 that the cumulative distribution of daily VMT for the INRIX data from Maryland exceeds the national average by up to $10 \%$. The "Daily VMT Distribution" sensitivity conducts a new set of EVI-Pro simulations using a subset of the INRIX GPS data which more closely resembles the national distribution of daily VMT. As expected, this scenario decreases infrastructure requirements overall by approximately $18 \%$ for both non-residential L2 and DCFC. 
Non-residential L2 Plug Count
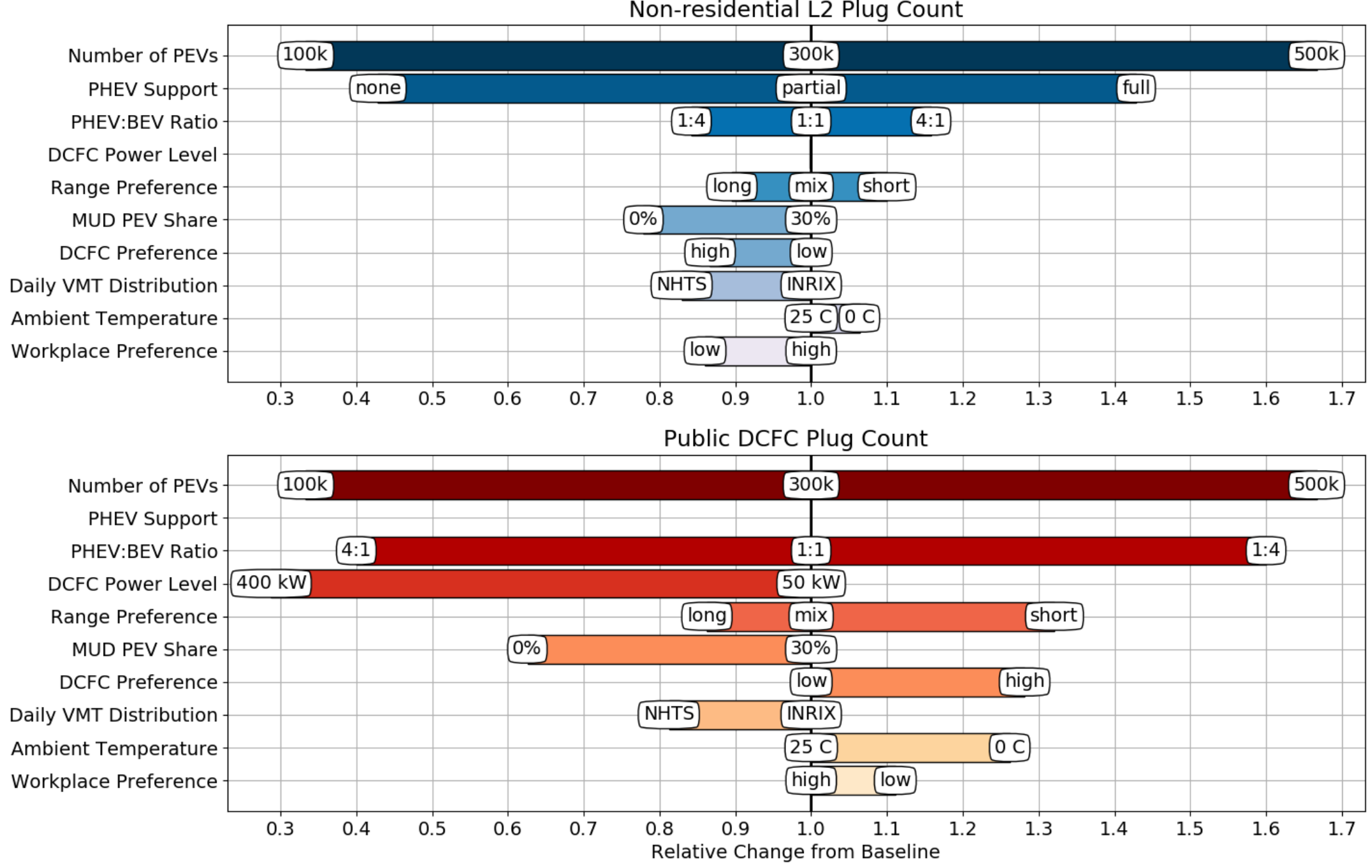

Figure 13. Results of parametric sensitivity analysis for non-residential (work and public) L2 plugs (top) and fast charging (bottom).

Results are presented as relative to baseline shown in Section 5.1. 
Finally, ambient temperature is swept from $25^{\circ} \mathrm{C}\left(77^{\circ} \mathrm{F}\right)$ in the baseline scenario to $0^{\circ} \mathrm{C}\left(32^{\circ} \mathrm{F}\right)$ in the "Ambient Temperature" sensitivity. Ambient temperature is incorporated in the EVI-Pro model through adjustments made to driving efficiency (as a result of cabin heating/cooling loads and battery efficiency impacts) and to DCFC power levels (modulations to charge power based on battery temperature) as discussed in previous studies (Wood et al. 2017). The sensitivity analysis neglects hot ambient conditions as cold conditions are modeled as having a more significant impact on PEV driving and charging efficiency. Maryland simulations show cold ambient temperature increasing demand for non-residential L2 by $6 \%$ and increasing DCFC demand by $26 \%$. 


\subsection{Simulated Charging Loads, Baseline}

While the primary output of EVI-Pro simulations are estimates for consumer charging infrastructure requirements, the highly resolved nature of EVI-Pro simulations lends itself well to estimating aggregate charging load profiles. This section presents simulated load profiles by time of day and location type from the baseline scenario presented in Section 5.1. Please refer to Appendix E for additional load profiles selected from the sensitivity analyses in Section 5.3.

Figure 14 shows the aggregated weekday charging load for the 300,000 PEVs assumed in the baseline scenario. This weekday profile represents approximately 3,200 megawatt-hours of electrical demand at residential and non-residential charging stations across Maryland (66\% residential) with a peak load of approximately 275 megawatts at 6 p.m. Note that simulations assume uncontrolled charging and do not consider any mechanisms for shifting load off-peak or for integration with renewable resources. In reality, Maryland utilities are likely to provide consumers with incentives for favorably aligning charging with non-PEV loads and constraints on the electrical grid (e.g., time of use rates).

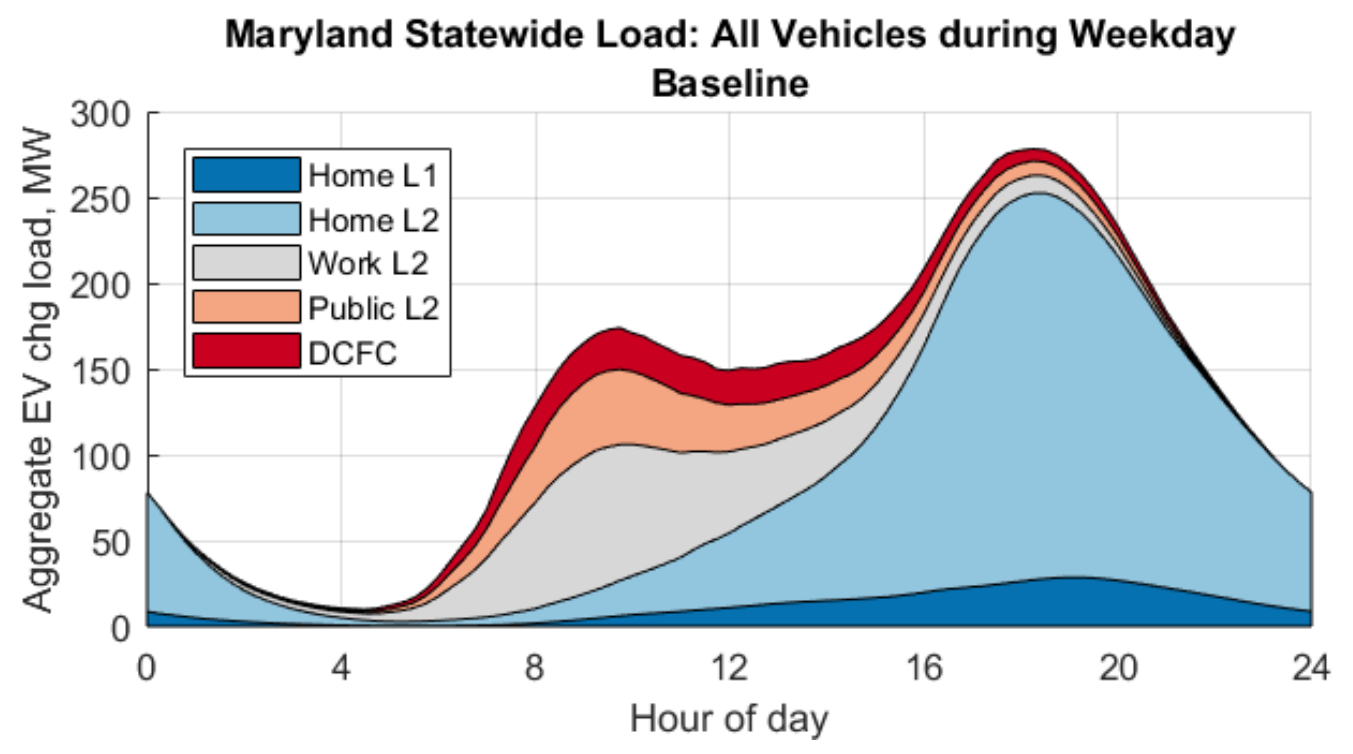

Figure 14. Aggregate statewide load profiles for a weekday, baseline 
Figure 15 decomposes the statewide charging load between residents of SUDs and MUDs (70\% and $30 \%$ of $300,000 \mathrm{PEVs}$, respectively). The SUD profile takes a familiar shape with approximately $90 \%$ of charging at home locations, primarily concentrated between 4 p.m. and 8 p.m. The MUD profile is exclusively non-residential (by definition) and concentrated between 8 a.m. and 12 p.m.
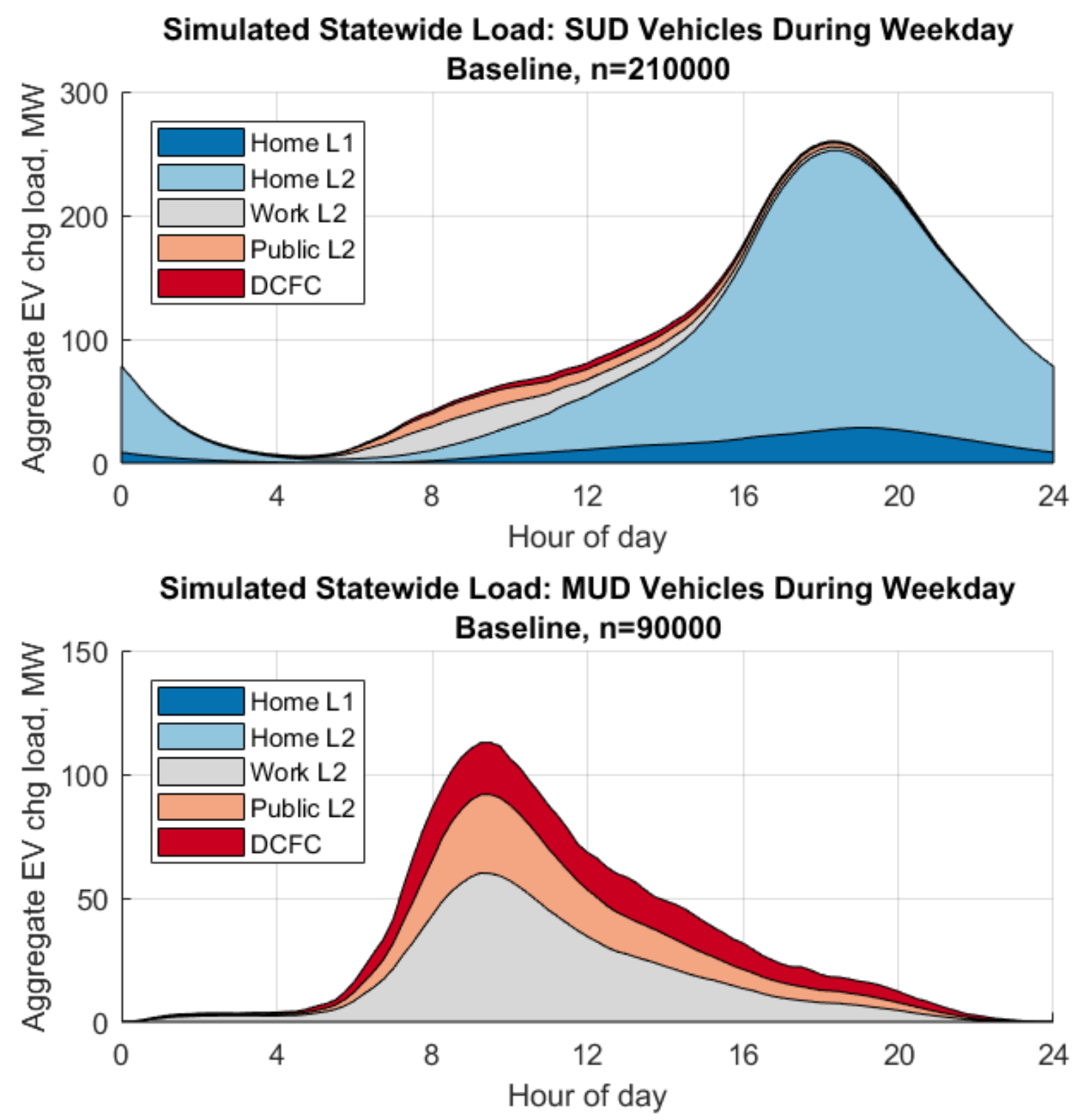

Figure 15. Statewide load profiles by charging type for a weekday, separated by residence type 
Figure 16 further decomposes the statewide load, this time segmenting the weekday loads from SUDs by the four PEV types considered in the study; note that the scales vary across plots, partially due to the different number of vehicles in each PEV type. The share of non-residential charging tends to increase as single-charge electric range decreases. This manifests in more charging events per day for short-range PEVs and a more uniformly distributed load across the day. Note that the BEV250 almost exclusively relies on L2 charging at home, resulting in a sharp peak in aggregate load in the early evening hours.
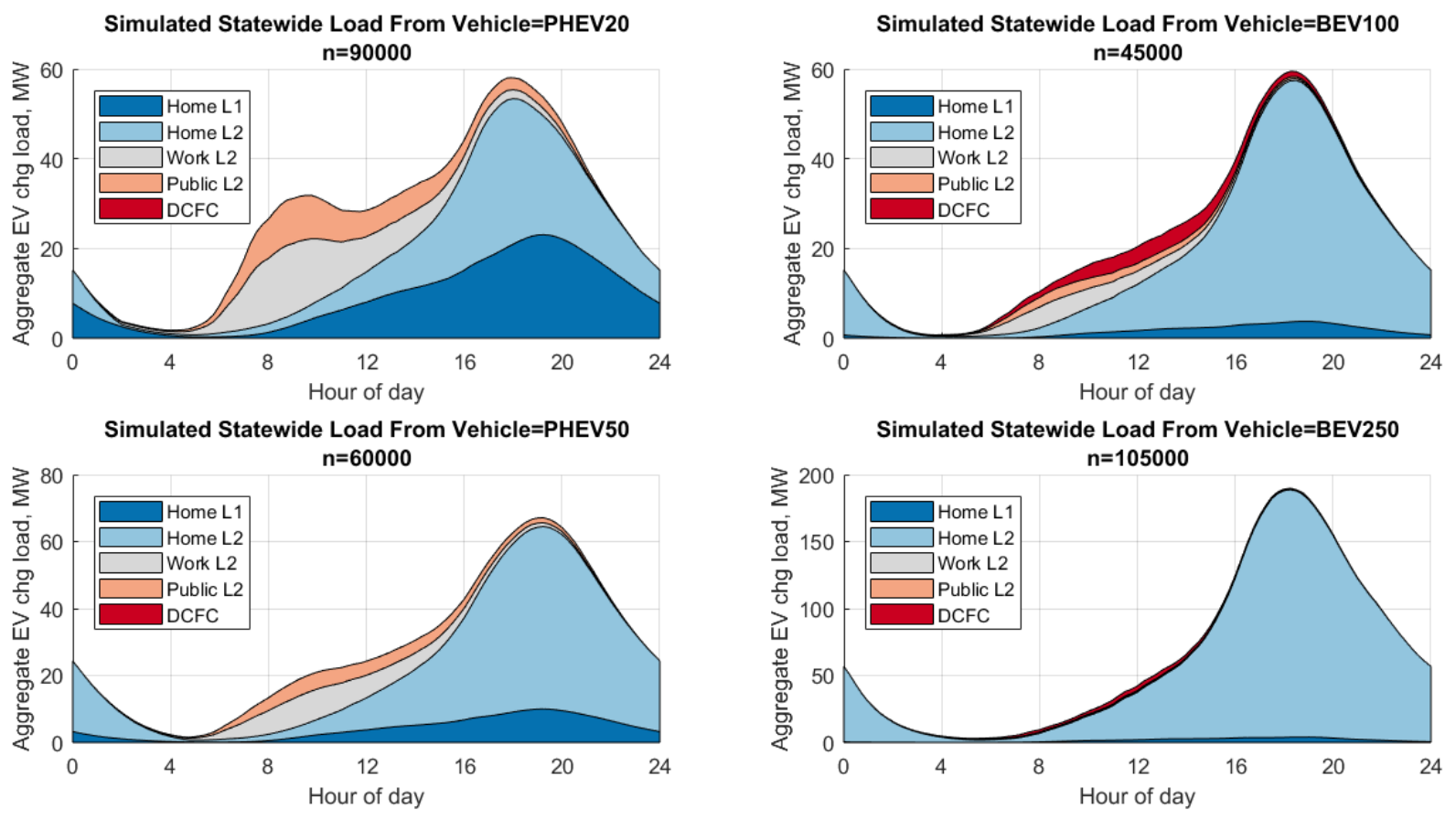

Figure 16. Statewide load profiles by charging type for a weekday, separated by vehicle type. The vehicles shown belong to SUD residents.

\subsection{Simulated Charging Loads, Time of Use Response}

The charging behavior in the previous section assumed that drivers immediately began charging their vehicles upon parking during dwells for which electricity is needed. Uncontrolled charging events create large load on the grid as drivers return home from work, often during times when the grid is already experiencing peak load from traditional demands. Electric utilities are beginning to respond to this problem through smart charging (Southern California Edison, 2016), or utility-controlled charging rates, and time of use (TOU) rates, or variable charging costs by time of day (Austin Energy, 2017). Although utilities may influence charging behavior, meeting travel requirements presents some demand constraints limiting the flexibility of the state-wide charging loads. For instance, drivers with high mileage demands and limited dwell opportunities may not be able to avoid charging during high priced periods. This section explores an alternate charging behavior where electric vehicle owners are offered a lower price during the late evening to incentivize delaying the beginning of their charge. 
Unlike the scenarios presented in section 5.4, charging scenarios were modeled with a variable residential utility rate. The price was low outside of the hours of 10AM and 8PM, representing a simplified approximation of the summer pricing offered by BG\&E for PEV loads at residences (Baltimore Gas and Electric Company, 2018). Every driver in this scenario is assumed to attempt to respond to the TOU rate and minimize their cost of residential charging. Figure 17 below shows the state-wide load profile and the relative residential utility rate by time of day. Consumers are assumed to delay their charging only if they can successfully meet their travel demand requirements.

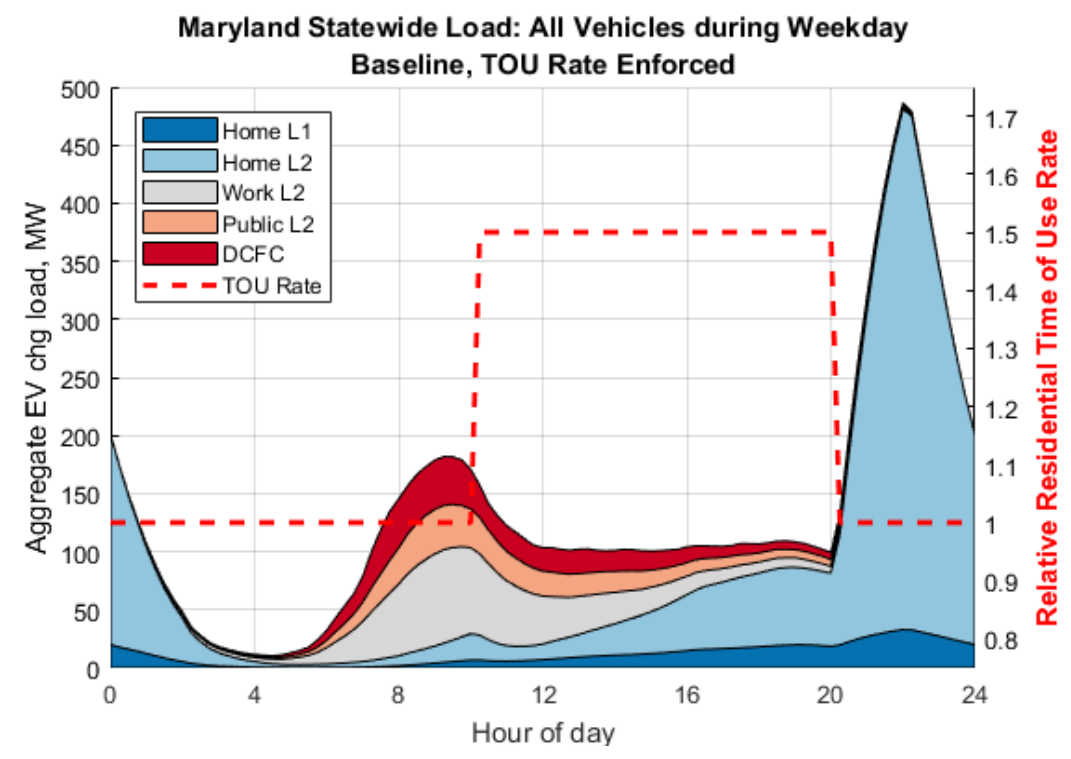

Figure 17. Aggregate statewide load profiles for a weekday with baseline assumptions and an applied TOU rate.

Results from the TOU pricing scenario revealed that nearly every vehicle was capable of delaying their residential charging to avoid increasing additional demand during peak hours of the day. A peak of approximately $480 \mathrm{MW}$ occurs at $10 \mathrm{PM}$ as compared to $280 \mathrm{MW}$ at $6 \mathrm{PM}$ in the uncontrolled scenario. The large increase in peak demand can be attributed to network-wide reaction to the TOU rate change; the baseline scenario peak is a function of arrival times at home, which are not uniform.

Note that these results are only intended to suggest the flexibility of the charging demand while still satisfying travel requirements; grid requirements such a power dispatching, transformer capabilities, etc. are not considered. 


\section{Summary}

This report examined the current PEV market and existing charging infrastructure in the state of Maryland. As of November 2017, 10,175 PEVs were registered in Maryland with 57\% as PHEVs and 43\% as BEVs. As of February 2018, Maryland had a total of 70 L1 plugs, 966 L2 plugs, and 172 DCFC plugs publicly accessible to PEV drivers.

Real-world GPS data were analyzed to understand the travel behavior of the state's residents. INRIX GPS data from 2015 containing a total of 5.6 million unique device identifiers, 20 million trips, 426 million miles of driving, and over 1.3 billion GPS waypoints were investigated for this analysis. Down sampling of these data for quality control purposes resulted in a sufficiently large data set for purposes of estimating charging infrastructure requirements for the 300,000 PEVs considered in this study, with checks made on the distribution of daily VMT and time of day drivers are on the road.

EVI-Pro simulations estimated that 17,400 workplace Level 2 plugs, 9,300 public Level 2 plugs, and 1,000 DCFC plugs are necessary to support 300,000 PEVs in Maryland by 2025. These estimates assume future PEV owners will drive PEVs in a manner consistent with present day gasoline vehicles using a combination of home, workplace, and public charging infrastructure to maximize electric VMT. Despite assuming 30\% of PEVs will be adopted by individuals without consistent access to home charging, simulations reveal $66 \%$ of statewide charging taking place at residential locations and approximately $90 \%$ for individuals with consistent access to home charging.

Although care has been taken to develop baseline estimates using the best available data, uncertainty remains. Parametric sensitivity analysis was used to explore impacts of multiple alternative scenarios. Results suggest that baseline estimates vary by double digit percentage points depending on evolving consumer preferences, charging behavior, and technology development.

Overall, this report finds that significant growth of Maryland's existing charging infrastructure network is necessary to support a goal of 300,000 PEVs by 2025. 


\section{References}

ABB. 2018. “ABB Ability Velocity Suite.” Accessed March 1, 2018. http://new.abb.com/enterprise-software/energy-portfolio-management/marketintelligence-services/velocity-suite

Austin Energy. 2017. "Residential Time-of-Use Rate EV360 Pilot Program". Accessed July 13, 2018. https://austinenergy.com/wcm/connect/88a9db10-fd11-4b51-837861db579988be/EV360OnePageInstallerOverview200617LM.PDF?MOD=AJPERES\&C $\underline{\mathrm{VID}}=1 \mathrm{SuHZ} 91$

Baltimore Gas and Electric Company. 2018. "Residential Electric Vehicle Time-Of-Use-Electric Schedule EV." Accessed June 26, 2018. https://www.bge.com/MyAccount/MyBillUsage/Documents/Electric/ScheduleEV.pdf

IHS Markit. 2017. "Vehicle Market Analysis: Registrations and Vehicles-in-Operation." Accessed March 1, 2018. https://www.ihs.com/products/automotive-market-dataanalysis.html

INRIX. "INRIX Analytics: Trips.” Accessed March 1, 2018. http://inrix.com/products/trips/

Melaina, Marc, Brian Bush, Joshua Eichman, Eric Wood, Dana Stright, Venkat Krishnan, David Keyser, Trieu Mai, and Joyce McLaren. 2016. National Economic Value Assessment of Plug-In Electric Vehicles: Volume I. DOE/GO-102016-4902. Golden: National Renewable Energy Laboratory, Golden, CO. http://www.nrel.gov/docs/fy17osti/66980.pdf

O'Malley, Martin, et al. 2013. "State Zero-Emission Vehicle Programs, Memorandum of Understanding." http://www.nescaum.org/documents/zev-mou-8-governors-signed20131024.pdf/

Santos, A., McGuckin, N., Nakamoto, H.Y., Gray, D., Liss, D. Summary of Travel Trends: 2009 National Household Travel Survey. FHWA-PL-11-022. United States Department of Transportation, Washington, DC. https://nhts.ornl.gov/2009/pub/stt.pdf

Southern California Edison. 2016. "Southern California Edison Plug-In Electric Vehicle (PEV) Smart Charging Pilot". Accessed July 13, 2018. http://www3.sce.com/sscc/law/dis/dbattach5e.nsf/0/0A867A0A088A764B88257FBE007 A30A5/\$FILE/A1410014-R1309011SCE_PEV_Smart\%20Charging\%20Pilot_Final\%20Report.pdf

U.S. Census Bureau. 2016. “American Community Survey (ACS).” Accessed March 1, 2018. https://www.census.gov/programs-surveys/acs/

U.S. Department of Energy, Alternative Fuels Data Center. "Alternative Fueling Station Locator." Accessed March 1, 2018. http://www.afdc.energy.gov/locator/stations/ 
Wood, Eric, Clement Rames, Matteo Muratori, Sesha Raghavan, and Marc Melaina. 2017. National Plug-In Electric Vehicle Infrastructure Analysis. DOE/GO-102017-5040. Golden: National Renewable Energy Laboratory. https://www.nrel.gov/docs/fy17osti/69031.pdf.

Wood, Eric, Clément Rames, Matteo Muratori, Sesha Raghavan, and Stanley Young. 2018. Charging Electric Vehicles in Smart Cities: An EVI-Pro Analysis of Columbus, Ohio. NREL/TP-5400-70367. Golden: National Renewable Energy Laboratory. https://www.nrel.gov/docs/fy18osti/70367.pdf 


\section{Appendix A. Existing Plug Counts by Utility Service Territory and County}

\begin{tabular}{|c|c|c|c|c|c|c|}
\hline Utility Service Territory & $\begin{array}{l}\text { L1 } \\
\text { Plugs }\end{array}$ & $\begin{array}{l}\text { L2 } \\
\text { Plugs }\end{array}$ & $\begin{array}{l}\text { DCFC } \\
\text { Plugs }\end{array}$ & $\begin{array}{l}\text { L1 } \\
\text { Stations }\end{array}$ & $\begin{array}{l}\text { L2 } \\
\text { Stations }\end{array}$ & $\begin{array}{l}\text { DCFC } \\
\text { Stations }\end{array}$ \\
\hline Baltimore Gas \& Electric & 56 & 580 & 84 & 27 & 237 & 38 \\
\hline Delmarva Power \& Light & 0 & 55 & 36 & 0 & 26 & 8 \\
\hline Potomac Edison & 0 & 50 & 15 & 0 & 28 & 5 \\
\hline Potomac Electric Power & 11 & 247 & 29 & 7 & 107 & 14 \\
\hline Southern Maryland Electric Coop & 3 & 31 & 7 & 3 & 20 & 2 \\
\hline Remaining Utilities & 0 & 3 & 1 & 0 & 3 & 1 \\
\hline County & $\begin{array}{l}\text { L1 } \\
\text { Plugs }\end{array}$ & $\begin{array}{l}\text { L2 } \\
\text { Plugs }\end{array}$ & $\begin{array}{l}\text { DCFC } \\
\text { Plugs } \\
\end{array}$ & $\begin{array}{l}\text { L1 } \\
\text { Stations }\end{array}$ & $\begin{array}{l}\text { L2 } \\
\text { Stations }\end{array}$ & $\begin{array}{l}\text { DCFC } \\
\text { Stations }\end{array}$ \\
\hline Allegany County & 0 & 0 & 0 & 0 & 0 & 0 \\
\hline Anne Arundel County & 13 & 75 & 9 & 5 & 33 & 5 \\
\hline Baltimore City & 9 & 265 & 33 & 6 & 90 & 17 \\
\hline Baltimore County & 32 & 130 & 12 & 15 & 60 & 5 \\
\hline Calvert County & 0 & 12 & 0 & 0 & 7 & 0 \\
\hline Caroline County & 0 & 0 & 0 & 0 & 0 & 0 \\
\hline Carroll County & 0 & 11 & 2 & 0 & 7 & 1 \\
\hline Cecil County & 0 & 6 & 22 & 0 & 2 & 3 \\
\hline Charles County & 3 & 16 & 7 & 3 & 11 & 2 \\
\hline Dorchester County & 0 & 1 & 2 & 0 & 1 & 1 \\
\hline Frederick County & 0 & 22 & 3 & 0 & 11 & 2 \\
\hline Garrett County & 0 & 10 & 0 & 0 & 5 & 0 \\
\hline Harford County & 0 & 23 & 2 & 0 & 14 & 1 \\
\hline Howard County & 0 & 58 & 12 & 0 & 25 & 5 \\
\hline Kent County & 0 & 4 & 0 & 0 & 2 & 0 \\
\hline Montgomery County & 1 & 168 & 26 & 1 & 86 & 13 \\
\hline Prince George's County & 12 & 112 & 17 & 7 & 39 & 5 \\
\hline Queen Anne's County & 0 & 10 & 2 & 0 & 4 & 1 \\
\hline Somerset County & 0 & 5 & 0 & 0 & 3 & 0 \\
\hline St. Mary's County & 0 & 0 & 0 & 0 & 0 & 0 \\
\hline Talbot County & 0 & 4 & 0 & 0 & 3 & 0 \\
\hline Washington County & 0 & 6 & 13 & 0 & 5 & 4 \\
\hline Wicomico County & 0 & 7 & 8 & 0 & 4 & 2 \\
\hline Worcester County & 0 & 21 & 2 & 0 & 9 & 1 \\
\hline
\end{tabular}




\section{Appendix B. Maryland Housing Stock by Size and Ownership Status (with NREL Assumptions Regarding Potential Availability of Home Charging)}

\begin{tabular}{lll}
\hline & $\begin{array}{l}\text { Maryland } \\
\text { Shares } \\
\text { (sums }\end{array}$ & $\begin{array}{l}\text { Assume } \\
\text { Home }\end{array}$ \\
& $100 \%$ ) & Charging? \\
\hline Estimates: Owner-occupied housing units: 1, detached & $47.7 \%$ & yes \\
Estimates: Owner-occupied housing units: 1, attached & $14.3 \%$ & yes \\
Estimates: Owner-occupied housing units: 2 & $0.2 \%$ & yes \\
Estimates: Owner-occupied housing units: 3 or 4 & $0.2 \%$ & yes \\
Estimates: Owner-occupied housing units: 5 to 9 & $0.6 \%$ & no \\
Estimates: Owner-occupied housing units: 10 to 19 & $1.2 \%$ & no \\
Estimates: Owner-occupied housing units: 20 to 49 & $0.5 \%$ & no \\
Estimates: Owner-occupied housing units: 50 or more & $0.9 \%$ & no \\
Estimates: Owner-occupied housing units: Mobile home & $1.0 \%$ & yes \\
Estimates: Owner-occupied housing units: Boat, RV, van, etc. & $0.0 \%$ & yes \\
Estimates: Renter-occupied housing units: 1 , detached & $5.4 \%$ & yes \\
Estimates: Renter-occupied housing units: 1, attached & $6.7 \%$ & no \\
Estimates: Renter-occupied housing units: 2 & $1.2 \%$ & no \\
Estimates: Renter-occupied housing units: 3 or 4 & $1.9 \%$ & no \\
Estimates: Renter-occupied housing units: 5 to 9 & $4.2 \%$ & no \\
Estimates: Renter-occupied housing units: 10 to 19 & $7.0 \%$ & no \\
Estimates: Renter-occupied housing units: 20 to 49 & $1.6 \%$ & no \\
Estimates: Renter-occupied housing units: 50 or more & $5.1 \%$ & no \\
Estimates: Renter-occupied housing units: Mobile home & $0.3 \%$ & no \\
Estimates: Renter-occupied housing units: Boat, RV, van, etc. & $0.0 \%$ & no \\
\hline
\end{tabular}




\section{Appendix C. PEV Projections by County}

\begin{tabular}{|c|c|c|c|c|c|}
\hline County & PHEV20 & PHEV50 & BEV100 & BEV250 & Total \\
\hline Allegany County & 242 & 162 & 121 & 283 & 808 \\
\hline Anne Arundel County & 9,291 & 6,194 & 4,646 & 10,840 & 30,971 \\
\hline Baltimore County & 11,213 & 7,475 & 5,607 & 13,080 & 37,375 \\
\hline Calvert County & 1,584 & 1,056 & 792 & 1,848 & 5,280 \\
\hline Caroline County & 255 & 170 & 127 & 297 & 849 \\
\hline Carroll County & 2,050 & 1,367 & 1,025 & 2,392 & 6,834 \\
\hline Cecil County & 822 & 548 & 411 & 959 & 2,740 \\
\hline Charles County & 2,052 & 1,368 & 1,026 & 2,394 & 6,840 \\
\hline Dorchester County & 248 & 165 & 124 & 289 & 826 \\
\hline Frederick County & 4,314 & 2,876 & 2,157 & 5,033 & 14,380 \\
\hline Garrett County & 122 & 82 & 61 & 143 & 408 \\
\hline Harford County & 2,664 & 1,776 & 1,332 & 3,108 & 8,880 \\
\hline Howard County & 7,351 & 4,900 & 3,675 & 8,576 & 24,502 \\
\hline Kent County & 372 & 248 & 186 & 434 & 1,240 \\
\hline Montgomery County & 25,842 & 17,228 & 12,921 & 30,149 & 86,140 \\
\hline Prince George's County & 9,624 & 6,416 & 4,812 & 11,228 & 32,080 \\
\hline Queen Anne's County & 669 & 446 & 335 & 781 & 2,231 \\
\hline St. Mary's County & 1,397 & 931 & 698 & 1,629 & 4,655 \\
\hline Somerset County & 96 & 64 & 48 & 112 & 320 \\
\hline Talbot County & 678 & 452 & 339 & 791 & 2,260 \\
\hline Washington County & 1,179 & 786 & 590 & 1,376 & 3,931 \\
\hline Wicomico County & 780 & 520 & 390 & 910 & 2,600 \\
\hline Worcester County & 535 & 356 & 267 & 624 & 1,782 \\
\hline Baltimore city & 6,620 & 4,414 & 3,310 & 7,724 & 22,068 \\
\hline Total & 90,000 & 60,000 & 45,000 & 105,000 & 300,000 \\
\hline
\end{tabular}




\section{Appendix D. Electric Vehicle Supply Equipment Projections by County}

\begin{tabular}{llll}
\hline County & Work L2 & Public L2 & DCFC \\
\hline Allegany County & 40 & 29 & 9 \\
Anne Arundel County & 1,660 & 867 & 107 \\
Baltimore County & 2,070 & 1,202 & 101 \\
Calvert County & 189 & 140 & 31 \\
Caroline County & 24 & 29 & 14 \\
Carroll County & 278 & 167 & 42 \\
Cecil County & 118 & 70 & 13 \\
Charles County & 202 & 145 & 17 \\
Dorchester County & 36 & 34 & 10 \\
Frederick County & 797 & 421 & 72 \\
Garrett County & 21 & 15 & 6 \\
Harford County & 472 & 272 & 40 \\
Howard County & 1,532 & 760 & 104 \\
Kent County & 79 & 65 & 13 \\
Montgomery County & 5,299 & 2,669 & 205 \\
Prince George's County & 1,677 & 985 & 82 \\
Queen Anne's County & 101 & 48 & 19 \\
St. Mary's County & 197 & 104 & 14 \\
Somerset County & 33 & 14 & 8 \\
Talbot County & 104 & 49 & 18 \\
Washington County & 193 & 103 & 22 \\
Wicomico County & 113 & 89 & 12 \\
Worcester County & 76 & 64 & 9 \\
Baltimore city & 2,084 & 961 & 64 \\
Total & $\mathbf{1 7 , 3 9 3}$ & $\mathbf{9 , 2 9 9}$ & $\mathbf{1 , 0 3 4}$ \\
\hline & & & \\
\hline
\end{tabular}




\section{Appendix E. Select Load Profiles from Sensitivity Analysis}
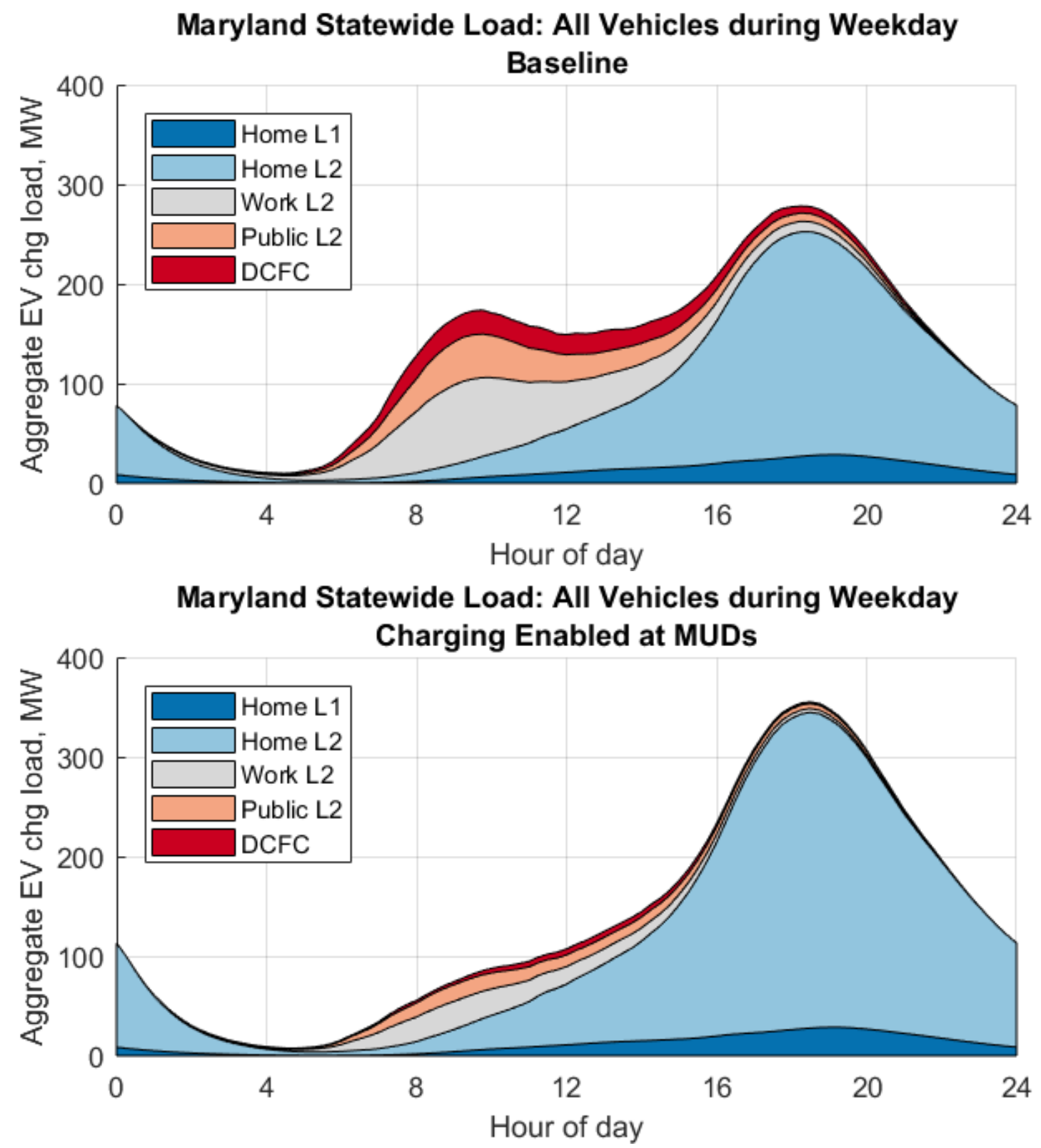

Figure E1. Aggregate statewide weekday load profiles with $30 \%$ MUD share. Top: No residential charging at MUDs. Bottom: L2 residential charging available at MUDs. 

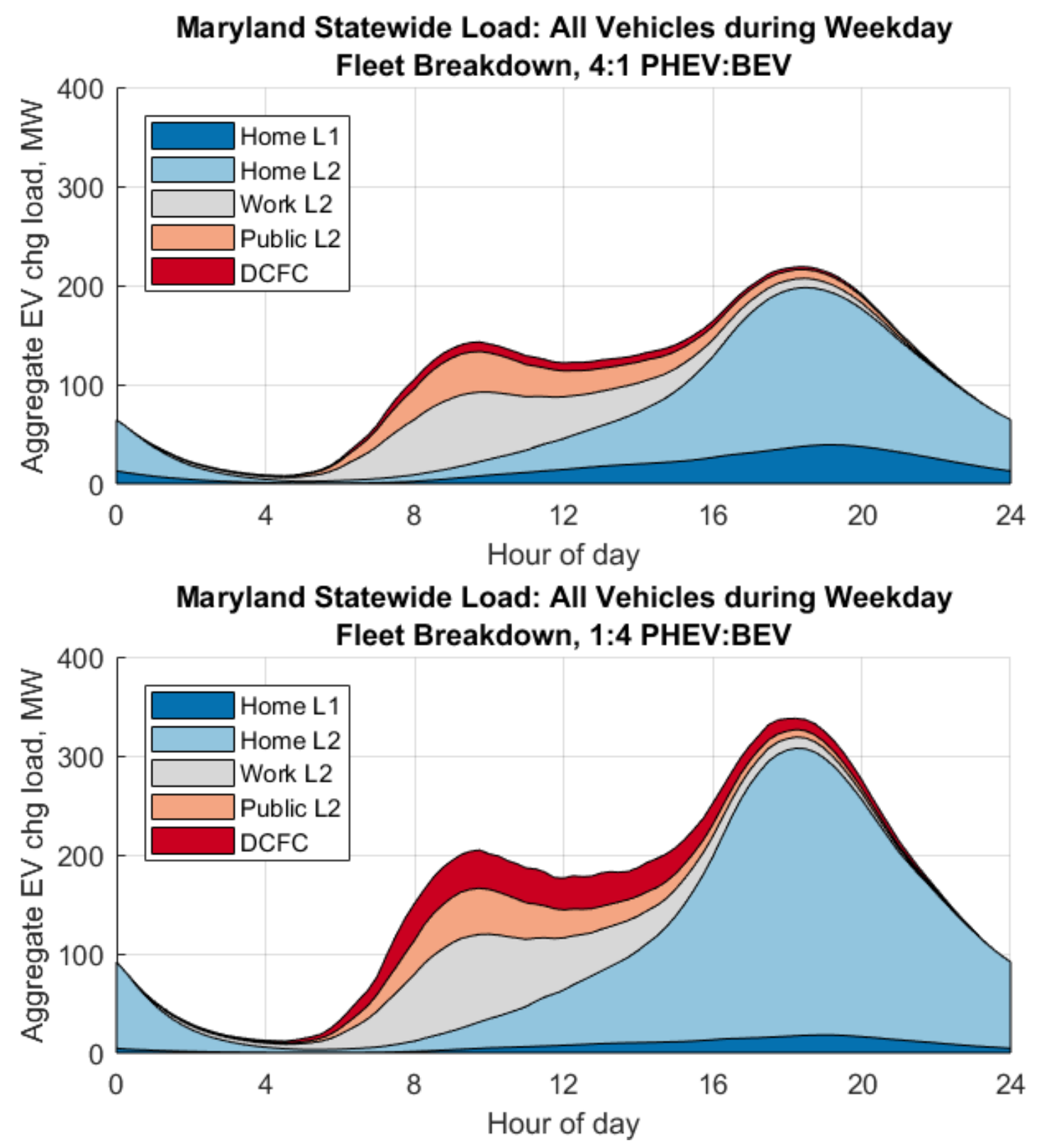

Figure E2. Aggregate statewide weekday load profiles. Top: 4:1 PHEV:BEV ratio. Bottom: 1:4 PHEV:BEV ratio. 

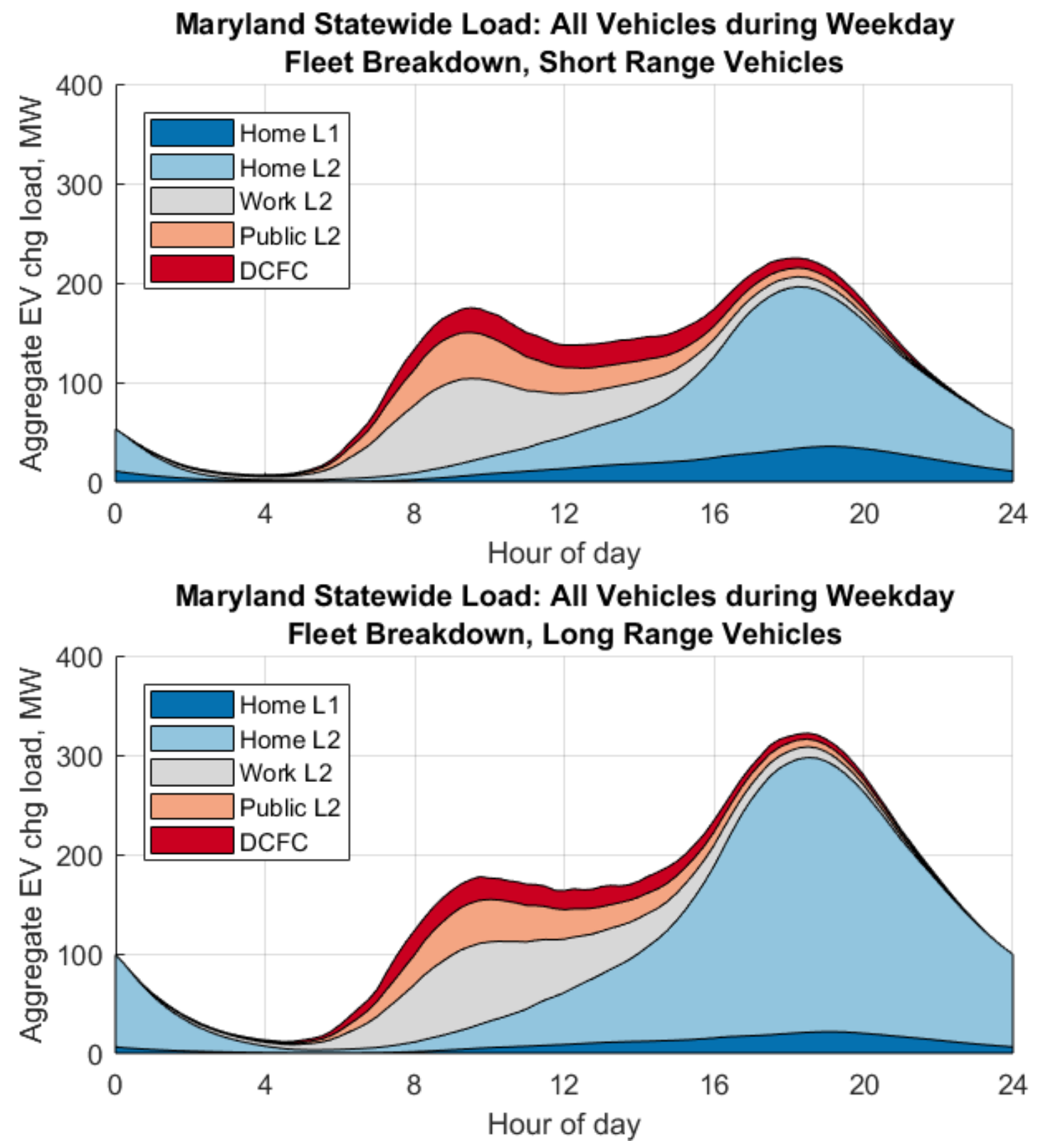

Figure E3. Aggregate statewide weekday load profiles. Top: Short-range PEV scenario. Bottom: Long-range PEV scenario. 